Chapman University

Chapman University Digital Commons

ESI Working Papers

Economic Science Institute

2015

\title{
Language and Cooperation in Hominin Scavenging
}

Bart J. Wilson

ChapmanUniversity, bjwilson@chapman.edu

Samuel R. Harris

Chapman University

Follow this and additional works at: https://digitalcommons.chapman.edu/esi_working_papers

Part of the Econometrics Commons, Economic Theory Commons, and the Other Economics Commons

\section{Recommended Citation}

Wilson, B.J, \& Harris, S.R. (2015). Language and cooperation in hominin scavenging. ESI Working Paper 15-29. Retrieved from http://digitalcommons.chapman.edu/esi_working_papers/191

This Article is brought to you for free and open access by the Economic Science Institute at Chapman University Digital Commons. It has been accepted for inclusion in ESI Working Papers by an authorized administrator of Chapman University Digital Commons. For more information, please contactlaughtin@chapman.edu. 


\section{Language and Cooperation in Hominin Scavenging}

\section{Comments}

Working Paper 15-29

This working paper was later published as:

Wilson, B., \& Harris, S. (2017). Language and cooperation in hominin scavenging. Evolution and Human

Behavior, 38(3), 376-396. doi: 10.1016/j.evolhumbehav.2016.11.009 


\title{
Language and Cooperation in Hominin Scavenging ${ }^{\ddagger}$
}

\author{
Bart J. Wilson ${ }^{*}$ and Samuel R. Harris ${ }^{* *}$ \\ Economic Science Institute \\ Chapman University
}

14 September 2015

\begin{abstract}
Bickerton $(2009,2014)$ hypothesizes that language emerged as the solution to a scavenging problem faced by proto-humans. We design a virtual world to explore how people use words to persuade others to work together for a common end. By gradually reducing the vocabularies that the participants can use, we trace the process of solving the hominin scavenging problem. Our experiment changes the way we think about social dilemmas. Instead of asking how does a group overcome the selfinterest of its constituents, the question becomes, how do constituents persuade one another to work together for a common end that yields a common benefit?
\end{abstract}

Key Words: language, cooperation, scavenging, experimental economics

JEL Classifications: C92, D70, Z13

\footnotetext{
${ }^{\ddagger}$ We gratefully acknowledge the financial support of Chapman University and the National Science Foundation (SES 1123803). Wilson specifically thanks the Property and Environment Research Center (PERC) for their generous hospitality and financial support as a Lone Mountain Fellow during the summer of 2015, and Harris thanks the International Foundation for Research in Experimental Economics for their generous support to work on this project as a Summer Scholar from 2012-15. We also thank Jeffrey Kirchner for his creative software programming; Bailey Ennis, Jeremiah Ludwinski, Keane Tarrosa, and Sean Weller for their research assistance on this project in its nascence; Joshua Ball, Benjamin Chalmers, Gillian Courtney, Alex Feldman, J. Trent Gerdeman, and Mary Howard for diligently fact checking our narratives; and Jan Osborn and Stephen Semos for their meticulous comments on an early draft of the paper. Finally, we thank Frank Wolak, Erez Yoeli, and seminar participants at PERC for valuable conversations and comments that have improved the paper. The data and source code are available upon request and upon acceptance for publication in a journal.

*Email: bartwilson@gmail.com

${ }^{* *}$ Email: samuelroberth@gmail.com
} 


\section{The Origins of Language and Cooperation}

Bickerton (2009) makes the bold claim that "without understanding how language evolved, we can never hope to explain or understand ourselves" (p. 12). Language, he argues, is fundamental to the story of human evolution. Not only is language the product of an evolved, human-like mind, it is a key ingredient in the recipe for one. Without the cooperative outcomes made possible through language, we would lack access to high calorie meat necessary for larger, more complex brains. Language is necessary to coordinate behavioral solutions to complex problems. Yet it is the potential benefits of solving those cooperation problems that comprise the evolutionary demand to evolve more complex brains. Understanding how humans made language is thus fundamental to understanding our own evolution, i.e., how language made us human. ${ }^{1}$ And so, to understand the genesis of language, we must consider the environmental realities faced by Pleistocene proto-humans, two million years ago, on the savannahs of East Africa. From that context, we can rationally reconstruct the cause for the genesis of language, which Bickerton hypothesizes was the demand of a "power scavenging" niche.

The "power scavenging" niche, as Bickerton $(2009,2014)$ terms it, was one in which protohumans quickly located carcasses of dead animals and scavenged meat from them with the help of other band members. ${ }^{2}$ This wasn't an open niche. To access these calorie-rich carcasses, proto-humans had to fend off large fanged-and-clawed predators. In other words, to develop this niche as a reliable source of food, non-kin proto-humans had to work together for the common purposes of defending the carcass and consuming the spoils at their catchment site (Domínguez-Rodrigo and Pickering, 2003). Nonkin proto-humans also had to convince other members of their band that this was a worthwhile activity. Recruitment and working together for a common purpose were thus the fundamental problems language had to solve in order for humans to occupy the power scavenging niche.

The Oldupai environment in Tanzania, a nearly 2 million year old site of early hominin activity, provides the backdrop for Bickerton's thesis. It was rich in both geographic and ecological diversity, with a large lake surrounded by the wetlands, streams, and oases that were focal points for animal and hominin activity (Ashley, 2009). These focal points supported thousands of organisms ranging in size from smaller gazelle-like animals to elephant-like megafauna (Domínguez-Rodrigo et al., 2014). These animals roamed the area, grazing in the wetlands and areas surrounding streams and oasis. Occasionally, they would die from old age or natural events, leaving a tremendous source of potential calories for early hominins - but only if they could cut through tough hides and access the meat inside before other scavengers, like any one of six genera of big cats, could consume the carcass. Bickerton theorizes that it was in their progressive occupation of this niche that proto-humans came to use the first words.

Bickerton bases his thesis on the theory of niche construction (Odling-Smee, Laland, and Feldman, 2003). Niche construction theorizes that organisms, by altering and expanding their niches, are capable of influencing their evolutionary paths as feedback loops form from environments to

\footnotetext{
${ }^{1}$ The subtitle of Bickerton's book is "How Humans Made Language, How Language Made Humans."

${ }^{2}$ See also Bickerton and Szathmáry (2011).
} 
organisms and from organisms to environments. By gradually filling the niche of power scavenging, proto-humans thus guided their own evolution, leading, crucially, to the emergence of language.

Language would be central to constructing such a scavenging niche. Except for ants and bees, all other animal communication systems are bound to the here and now. To power scavenge from a known carcass beyond the hill, proto-humans needed a way to communicate about objects and events that are spatiotemporally distant from the perceivable present. Language solves this fundamental problem of displacement in communication.

While it is clear that displacement through some form of language was required to solve the power scavenging problem, it is unclear what specific words and concepts were necessary or sufficient. Additionally, it is unclear how proto-human dispositions may have interacted with language to bring about certain behaviors. Our project attempts to shed a little light on these questions with a laboratory experiment. Bickerton (2009) himself proposes and explains the benefits of such a project (p. 228, italics added):

\begin{abstract}
What is needed here is the opening of a new field of inquiry-the study of hypothetical early vocabularies and the communicative consequences of different word choices in forming vocabularies of a hundred words on down.

The beauty of this field is that you can actually do experiments: you can give such vocabularies to real-life subjects-not just simulated cyber-agents, but flesh and blood people-and get them to perform varying types of communicative tasks with these limited resources. Of course you can't actually replicate Stone Age languages-we are humans and they weren't-but you'll at least establish upper limits on what could have been produced, and I'm willing to bet that in the process, facts we never knew about language will emerge.
\end{abstract}

But why should an economist be interested in the genesis of language? Because the "best part of [Bickerton's] story" on the genesis of language is that "it gives cooperation for free" (p. 167), and economists are both keen to explain cooperation and skeptical of claims about free lunches. Bickerton argues that cooperation comes for free with the selection pressures for language because exchanging information about scavenging for carcasses is only valuable if some band members defend against predators while others collect the meat. ${ }^{3}$ As Bickerton (2009) succinctly puts it, "I get the benefit only if I can persuade others to help me, and I can only get others to help me by giving them information [beyond the here and now]. If we can cooperate, we all gain; if not, we all lose" (p. 166). From the very beginning, then, the foremost function of language is to persuade, and it is about persuading others to work together for a common end that yields a common benefit.

The purpose of this essay is to observe the persuasive work that words do as part of the process of solving a hominin scavenging problem. We design a virtual world in which the inhabitant population cannot sustain itself without scavenging for meat. As part of the experiment, we gradually vary and restrict the vocabularies available to our flesh and blood participants as they make decisions for real salient payoffs. We begin with the unbounded set of natural language and conclude with a vocabulary

\footnotetext{
${ }^{3}$ Nowak (2006) defines a cooperator as "someone who pays a cost, $c$, for another individual to receive a benefit, $b$ " (p. 1560). By that definition, a vampire bat that regurgitates some blood for another member of the colony is a cooperator. In this paper we distinguish doing something costly for another individual to receive a benefit from doing something costly with another individual to receive a common benefit. Homo sapiens is the only species that regularly cooperates by recruiting non-kin to do something costly for a common benefit (Bickerton 2009).
} 
that consists of 11 non-word symbols. In between, we take a bounded set of 26 words and 11 non-word symbols and, systematically over the course of three treatment conditions, drop a mere 10 words until the participants fail to solve the scavenging problem. With each successive vocabulary the participants progressively lose their ability to directly communicate features of the problem beyond the here and now. Our project leaves it to our participants to discover the collective scavenging problem for themselves. In doing so, we can observe the process by which participants themselves (1) establish a common end with other people, (2) form groups to solve the problem of achieving the common end, and (3) maintain the group in face of ongoing competing interests and desires.

Vesterlund (forthcoming) updates Ledyard's (1995) initial survey of the voluminous literature on public goods experiments with references to studies that endogenize group formation and test conditions, including free form communication, that support higher contributions. Our inquiry is not into whether and by what degree communication improves cooperation, but into how people use words to persuade each other and solve a cooperation problem. To do so, our experiment implements the very problem that Bickerton hypothesizes required a means for humans to solve cooperative problems, to wit, language. By controlling which words the participants can use, we trace the conceptual work that language does initiating and sustaining profitable cooperation. We also observe what our participants do and don't do when they fail to solve the scavenging problem.

\section{Experimental Design and Procedures}

Following Peltzman $(2000,2015)$, our project is unrepentantly descriptive. Rather than testing formal hypotheses for a set of treatment conditions specified in advance, we develop some facts with a series of successive treatment conditions that illuminate the process by which language solves a cooperative problem. Our project is also unabashedly artificial. Since we can't recreate the physical conditions under which protolanguage emerged, we use a computer laboratory to generate replicable conditions for scavenging. [The athletic director denied our request to use the stadium, saying something about the mess of recreating the Colosseum with lions, tigers, and jaguars.] Finally, given the nature of our data, the presentation of the results is unexpectedly ethnographic. As we shall see, most sessions fail to even come close to solving the scavenging problem, but one session per treatment is highly successful. We thus present our results as a systematic description of individual societies, garnered through observation and experimentation. This is largely accomplished by reporting what our participants say and do. Words, even unmeasured ones, are data too.

\section{Environment and Institution}

Each participant in the experiment controls a colored avatar to traverse the experimental world and interact with other participants' avatars. The world is divided into two regions: the western $1 / 3$ is designed as a gathering area, and the eastern $2 / 3$ is designed for power scavenging. Figure 1 displays a physical map of the entire world, which is 6300 pixels high and 30,240 pixels wide. Participants can only view an area of $1680 \times 1050$ pixels centered about their avatar. The colored rectangles in the west indicate the limited world view of the participant (see Figure 1). Avatars move at a speed of 350 pixels per second, which is accomplished by left clicking on a spot within their field of vision. Participants can 
track their position in the expansive world by using a mini-map, located in the top-left portion of the interface.

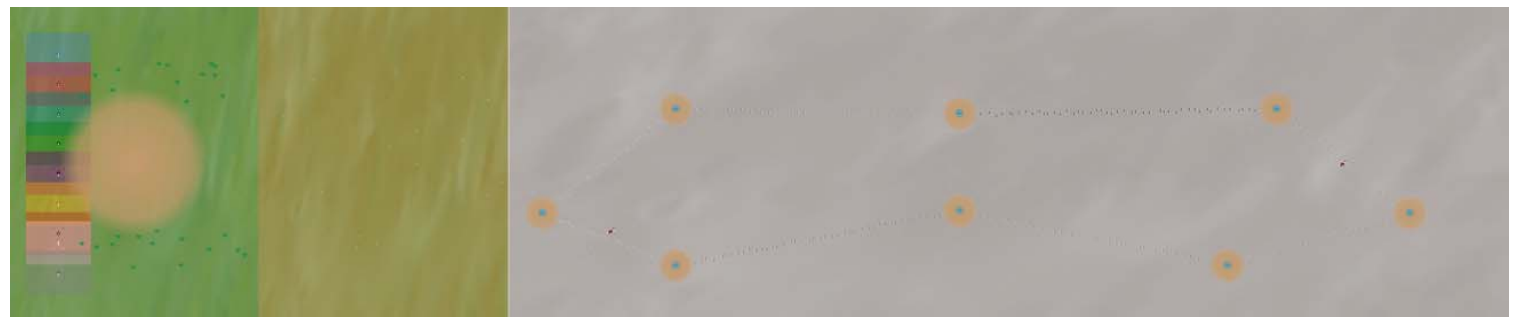

Figure 1. Bird's Eye View of the Virtual World with Avatars at their Starting Locations

Each experimental session includes 9 participants and consists of 27 periods, each lasting two minutes and 45 seconds. We subdivide each period into a day ( 2 minutes) and night (45 seconds). Participants earn cash based upon how "healthy" they are. At the beginning of each session each avatar is endowed with 50 units of "health." After every passing second, their current health score is converted into cash at a rate of $1 / 10$ of a US cent per health point. The interface displays their current rate of earning in terms of cents per minute. Every second, the participants lose 0.056 points of health, which is explained to the participants as "metabolism." An avatar's health can neither fall below zero nor rise above 100 points. The participants' task during the day is to replenish their health by collecting resources distributed throughout the virtual terrarium.

The instructions explain how to accumulate health by locating and gathering berries and bone marrow (see the Appendix for the instructions). Participants can collect berries and marrow by right clicking berries or marrow when they are nearby (see Figure 2). To be collected, these resources must be within 150-pixels of the avatar. Each berry and piece of marrow is worth, respectively, 1 and 1.2 health points. Participants are limited to gathering 6 berries and 5 pieces of marrow in each period. Because there are only 27 berries and 14 pieces of marrow in the gathering area, this limit on gathering means that only 4 of 9 avatars can offset their daily metabolism by gathering berries and marrow. Without offsetting their "metabolism," each avatar loses 9.24 units of health (= 165 seconds $x 0.056$ units/sec), per day. To offset solely with marrow and berries, a participant must collect 6 berries and 3 pieces of marrow. Of course, if participants collect more than 3 pieces of marrow, then the gathering area can only support two avatars who collect a full inventory of berries and marrow, and only three avatars in total could completely offset their metabolism. In sum, because the gathering area cannot support all 9 avatars, our design builds in an environmental pressure to push the avatars toward the power scavenging area.

The night is a time for the participants to relax and confer with each other. Without a daily break, the participants would incessantly roam the world in search of health points. The incentive to retire for the evening is that participants lose one health point per second if their avatar is not at an oasis. Participants may also exchange resources when they have retreated to an oasis for the night. The world contains nine oases, displayed as sandy circles in Figure 1. There is one large "home base" in the western gathering area, and eight smaller oases in the eastern power scavenging area. The mini-map displays the locations of any previously discovered oases. 

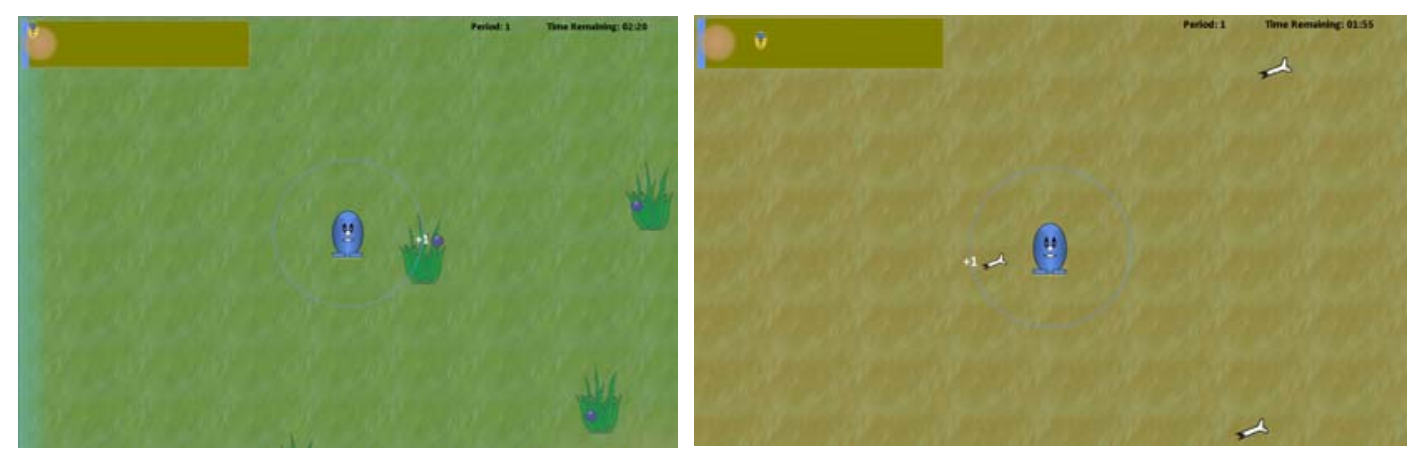

Figure 2. Screenshots of an Avatar Gathering Berries and Marrow

Unbeknownst to the participants, if they travel to the eastern $2 / 3$ of the world along a power scavenging path, they can discover meat, a third and richer source of health. As discussed below, some meat sources are left unguarded, while others are protected by a violent predator. When a participant right clicks on meat (as they have been instructed to do for berries or marrow), three icons appear (see Figure 3). The rollover text for each of the three icons from, left to right, is: "defend," "harvest," and "cancel." If a participant selects "defend," an animated shouting icon appears on the selected locations. For the unguarded meat, displayed in Figure 3, defending is not useful because there is no predator to defend against (more on defending later). If the participant selects "harvest," an animated axe icon appears at the selected location, swinging up and down on the meat. The third icon cancels either activity.

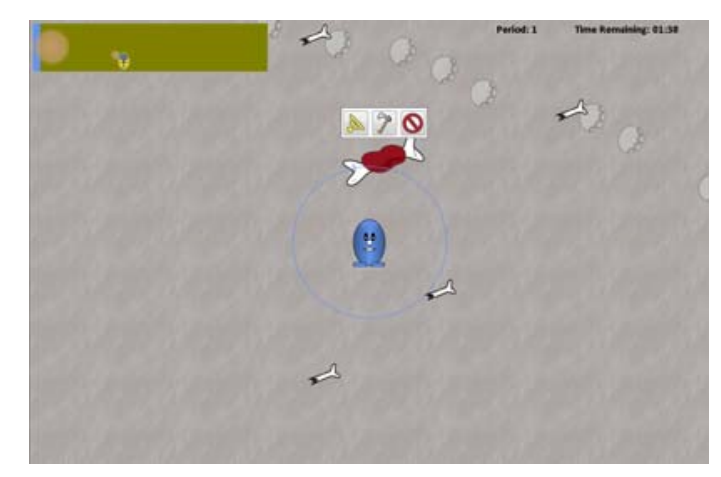

Figure 3. Screenshot of an Avatar Right Clicking on Meat

As the axe strikes the meat, 3 units of meat are added to the inventory of the avatar every 4 seconds, which we will call a 'tick.' Each unit of meat is worth 1.8 health points. An avatar can collect a maximum of 20 units of meat, but can only use 10 of them personally. The remainder can be given to another avatar by right clicking on the receiving avatar. Any amount of meat in excess of 10 perishes at the conclusion of the period. Berries, marrow, and meat can only be moved from avatar to avatar at night.

At the heart of our design is a predator which often guards the meat from the would-be scavengers (see Figure 4). If a lone avatar attempts to scavenge meat from a tiger, the tiger inflicts a 4 point loss in health every tick as the avatar extracts 1 unit of meat. This injury is mitigated, in whole or part, when other avatars defend the harvesting avatar against the tiger. To scavenge from a tiger 
without any damage, three other avatars must be simultaneously defending the harvester. With three defenders, a scavenger extracts 3 units of meat per tick instead of 1 . Table 1 reports how much damage the harvester incurs and how much meat is collected when there are 1, 2, and 3 defenders present. If multiple avatars attempt to scavenge at the same time, each scavenger incurs the same damage and collects the same amount of meat (see Table 1).

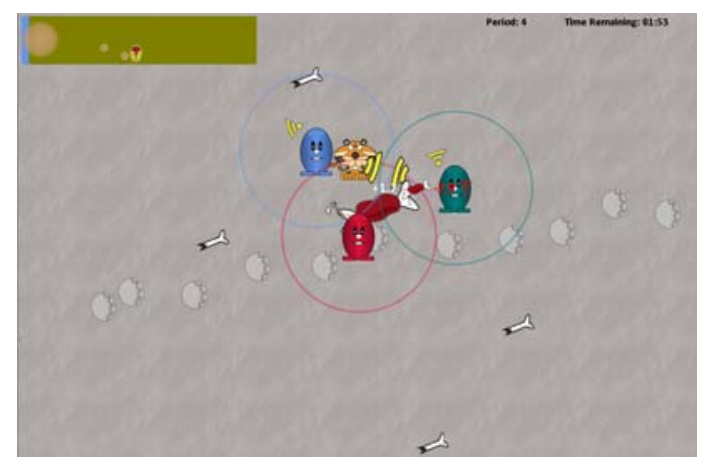

Figure 4. Two Avatars Defending a Third against a Tiger

In every period, there are two sources of meat near two different and equally-spaced oases in the power scavenging area. To make Bickerton's problem of recruitment nontrivial, the meat rotates around the power scavenging area after the participants have scavenged a minimum of 40 units of meat from one or both sources. ${ }^{4}$ With probability $p=0.8$, both sources of meat shift counterclockwise one oasis; with probability $1-p=0.2$, both shift two oases. Each time the meat moves, there is an independent 50 percent chance that a tiger will be simultaneously present at both locations. Each session begins with no tigers and a source of meat at the westernmost oasis.

Table 1. Damage and Meat per Tick when a Tiger is Present

\begin{tabular}{cccc}
\hline Defenders & Damage & Meat & Net Health \\
\hline 0 & 4 & 1 & -2.20 \\
1 & 3.2 & 1.5 & -0.50 \\
2 & 2.9 & 1.7 & 0.16 \\
$3+$ & 0 & 3 & 5.40 \\
\hline
\end{tabular}

\section{Initial Treatment Conditions}

The final feature of our design serves as the source of variation for our treatment conditions. At any time in the session, participants can chat with other participants. The text appears as a chat bubble next to the avatar. In our initial treatment, called Free Chat, participants can type out any combination of characters they desire. On the right side of the interface, participants also have access to arrows, numbers, symbols, and words that they may select with a click to add to their current line of text. Given that we did not know if our scavenging problem was too easy, such that every session could solve it, or too difficult such that none could solve it, we conducted six sessions of this treatment to serve as an initial baseline. If, with complete freedom to communicate, either every session or no session could

\footnotetext{
${ }^{4}$ If the participants scavenge a total of 10 units in period 1, 10 units in period 2, and 20 units in period 3, both sources of meat will move at the moment period 4 begins.
} 
solve the problems of recruitment and working together, our plan was to redesign the experiment to make the problem more or less difficult. As we discuss below, we observed neither possibility, and so the Free Chat treatment serves as our baseline.

For our second treatment, we evaluated the first and constructed a restricted lexicon. We compared the conversations and actions of the effectual and ineffectual Free Chat sessions to determine a limited set of arrows, numbers, symbols, and words. The open question is whether the participants could use only these 37 words/symbols to solve the problem, as the successful sessions in Free Chat had done.

Figure 5 displays this set of 37 words and symbols. The bottom 10 words (meat, switch, harvest, defend, follow, help, need, move, stay, together) do not appear on a participant's screen until they have right clicked on meat for the first time or unless someone else has given them some meat. ${ }^{5}$ In other words, we give the participants no indication that meat exists before they discover its costs and benefits for themselves. Before proceeding to the results, we recommend reading the experiment instructions in the Appendix.

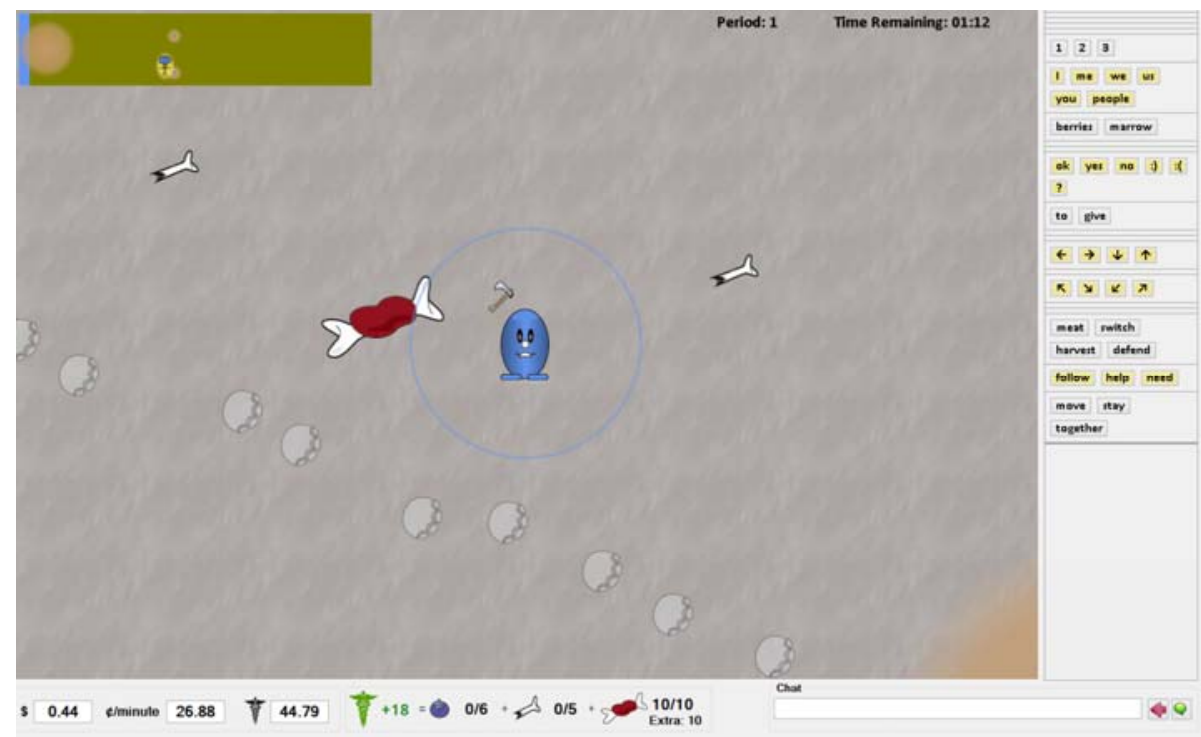

Figure 5. Complete Interface for the Bounded Treatment

In the next section, we report the actions and outcomes in the Free Chat sessions to justify our limited set of words, in what we will call the Bounded treatment. In Section IV, we discuss how these 6 new sessions compare with those in Free Chat. After the Bounded treatment, our research plan was to (a) systematically add or subtract from the list of words available to participants, intending to find a set of words/symbols that recreates the success and failure of the Free Chat treatment. Having found that set, (b) we planned to sequentially remove sets of words of until the entire treatment collapses, and no session could solve the recruitment problem of forming a band to scavenge.

\footnotetext{
${ }^{5}$ The icon for the meat inventory at the bottom of the screen also does not appear until the same conditions are met.
} 


\section{Procedures}

We conducted 6 replications in each of 6 separate treatment conditions. In total, 324 undergraduates participated. The participants were recruited from the general student body of a private university with 5,000 students. No student participated in more than one session. All students were randomly recruited via email, and were paid $\$ 7$ for showing up on time. Participants sat at visually-isolated computer terminals, where they privately read through self-paced instructions. Each was free to privately ask questions of the monitor throughout the experiment. Excluding the \$7 showup payment, participants earned $\$ 15.68$ on average $(\sigma=\$ 9.55)$ and were paid privately at the conclusion of the session. The maximum and minimum payments were $\$ 39.21$ and $\$ 1.58$, respectively. The participants usually completed reading the simple instructions in less than 5 minutes (see Appendix). Each session lasted no more than the 90 minutes for which the participants were recruited.

\section{Free Chat Results and the Selection of Words for the Bounded Treatment}

We evaluate the performance of a session by averaging, per period, the net health added from scavenging guarded meat. We calculate that metric by summing the total health added from (guarded) meat in a period and subtracting from it the total amount of health lost from engaging the tiger. We then average these results for the first 14 and last 13 periods in a session. Figure 6 reports the results for the sessions in the Free Chat baseline. We will refer to each session by its treatment name followed by its session number, e.g., Free Chat6.

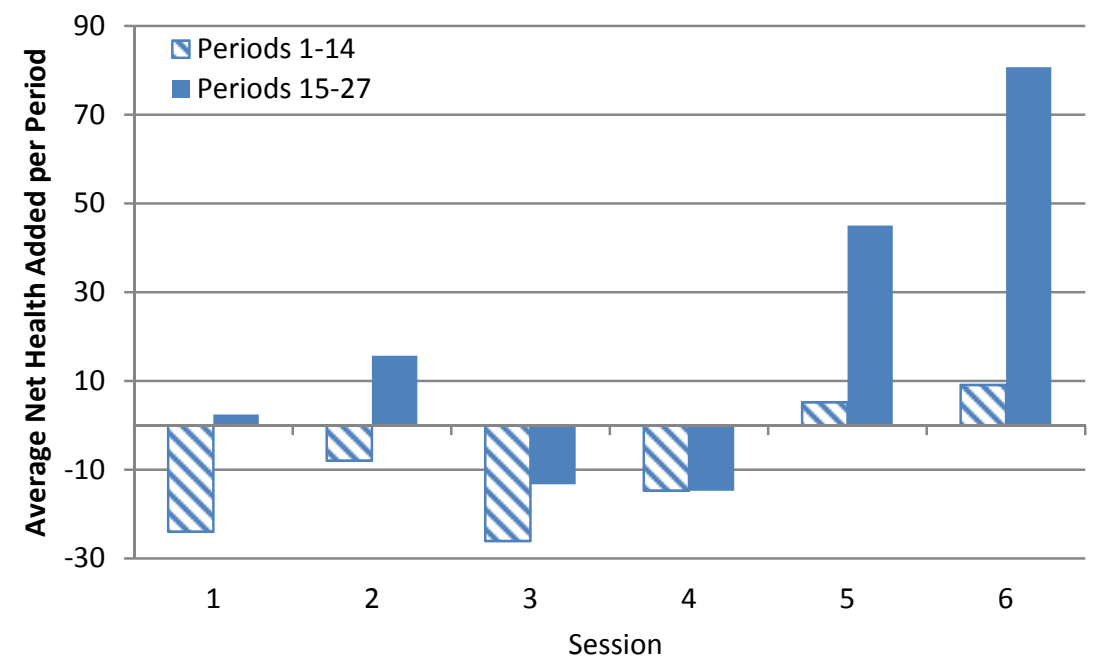

Figure 6. Free Chat Results for Scavenging Guarded Meat

\section{Recruitment Words}

Free Chat5 and 6, and to a much lesser degree, Free Chat2, are successful in solving the problem of forming a band to scavenge from tigers. We mined these sessions for the set of words that the participants used to recruit each other for power scavenging. We settled on six words: follow, need, stay, together, help, and move. Save for help and move, each of these words figures prominently in Free Chat 5 and 6 , where they were used by participants to solve the problem of recruitment and scavenging. 
"Follow"

We first note that the behavior we observe in the successful sessions is what we conspicuously find to be missing in the two worst performing sessions. Follow does not appear once in Free Chat 3 and 4. In contrast, participants in Free Chat5 and 6 use the word early on in their attempts to recruit others for scavenging:

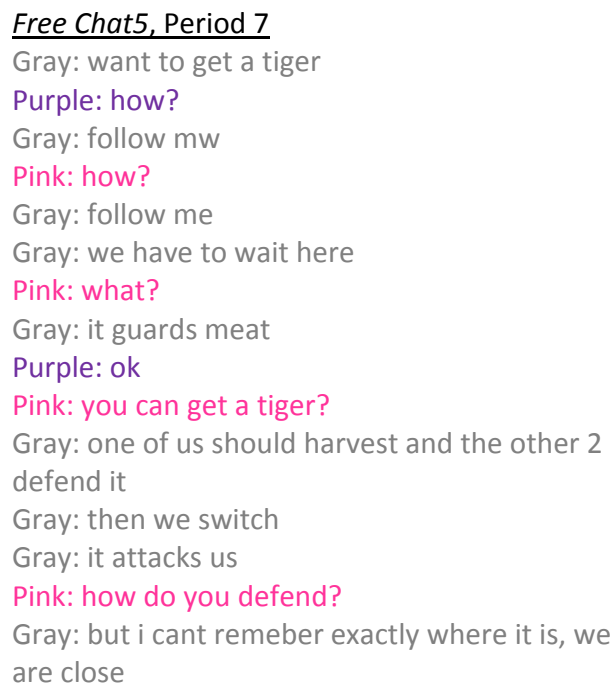

\author{
Gray: $\mathrm{u}$ right click the meat and click defend \\ Pink: $i$ think it is to the right \\ Free Chat6, Period 9 \\ Brown: follow me if you want moneys \\ Gray: wanna work together? \\ Purple: heyy / how so \\ Brown: we'd make bank \\ Gray: we can get the meat if some of us use the \\ yellow thing on the tiger \\ Green: how \\ Gray: and one person mines / we make way \\ more \\ Brown: more people use the yellow thing on the \\ tiger the mining doesn't cost life \\ Gray: there's a tiger to the oasis to the right \\ Green: swet lets do it \\ Gray: come with us! \\ Brown: follow for $\$ \$$ haha
}

Notice how this conversation captures two key features of Bickerton's problem for the emergence of language. First, we see displacement when the participants talk about something not present before their eyes. Secondly, the participants work to persuade others toward pursuing a common end by discussing the need for others to follow if they "want moneys". ${ }^{6}$

Using follow, however, is not sufficient for success as it also appears in Free Chat1 and 2. In Free Chat1, the problem is that others are not receptive to the idea. Early on, Orange attempts to recruit several participants to scavenge with him, saying "come" and "follow me" multiple times, but nobody follows him. There is only one instance of follow being used in Free Chat2, in an exchange at the end of period 21:

Pink: The tiger is over there to the right, hopefully it will be in the same spot next round

Teal: ill follow you

Saying "ill follow you", however, is not enough. Individuals must follow through on what they say. In the morning of period 22, Teal does not in fact follow Pink.

"Need"

Justifying why someone should follow you is a key part of the recruitment process, as the following conversations from Free Chat5 make clear:

\footnotetext{
${ }^{6}$ Because in future treatments the question mark and other non-word characters (excluding the period) will be symbols that the participants may use to converse with each other, we adopt the convention of placing the punctuation of the sentence outside the quotation marks when quoting participants.
} 
Period 8

Gray: we need more defenders

...

Gray: we need defenders and a harvester

Teal: how many do we have?

Gray: after a while, the harvester switches to

defender / we had 3 but idk where they are

Period 9

Gray: I think we need more defenders

Purple: is anyone else overin this area?

Period 16 (at oasis during night)

Orange: we need more people

Gray: yeah
Orange: let's find?

Gray: ok

Period 17 (scavenging from a tiger)

Orange: WHERE IS EVERYONE.

Gray: idk

Gray: we should stay as a big group and hunt the tiger

Orange: we just need to find more people

Red: yeah

[Brown joins them.]

Orange: PERFECT.

In Free Chat6, need is likewise an important element of the conversations to recruit, and it is used to reunite a band that has split up. In period 25, Purple, Teal, and Blue are scavenging from one tiger and Pink, Green, and Gray from another. Their separate conversations both emphasize the need for more people:

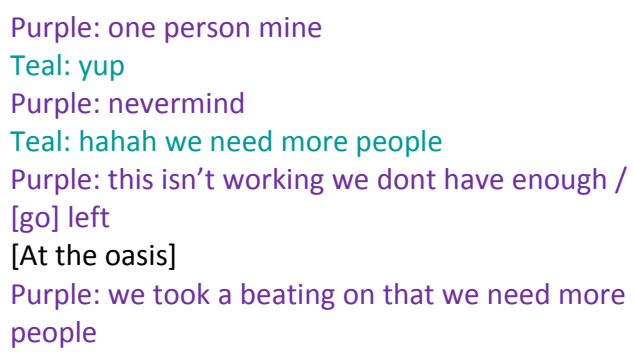

The band reunites after these conversations.

\author{
Purple: to the left. I thin kour crew went that \\ way and we may run into them \\ Blue: yeah oj kinda killed us on that one \\ Brown: that was a bad round \\ [Elsewhere] \\ Pink: OW / LOL / WE NEED MORE PPL \\ Gray: owwwww / ok well now we know
}

The participants in Free Chat1 also state that "we need more people to defend" and "we need to stick together", but they do not actively recruit people or follow through on these observations. In Free Chat2-4, the participants frequently bemoan that they "need marrow" and "need berries", but they never talk about "need[ing] people" for anything.

\section{"Stay together"}

Once members have been persuaded with good reasons to form a band, the central problem becomes maintaining that band in the face of competing interests (which is the reason why we put four pieces of marrow around each oasis). More often, participants use the more colloquial stick together as opposed stay, but the meaning is the same:

\section{Free Chat1, period 21}

Orange: where is everyone else / we need to

stick together

Gray: no idea. I don't like to stick with the

others. just me and you is better

Orange: alright then

Free Chat2, period 12

Red: if everyone stuck together we could all make a lot of money

Pink: yeah I think you are right. Definitely what

they are trying to get us to do
Free Chat2, period 25

Red: lets all styick together and get the tiger

Pink: yah i agree

Free Chat5, period 15

Gray: we need to get the group together Free Chat5, period 17

Gray: we should stay together as a big group and hunt the tiger

Orange: we just need to find more people

Red: yeah

[Brown joins.] 
Orange: PERFECT

...

Orange: TRY AND STICK TOGETHER

Gray: yeah together

Brown: TOGETHER

Free Chat6, period 14

Gray: sweet no tiger!!
Pink: FREE MEAT

Gray: but lets still stick together

Free Chat6, period 27

Blue: i thought we established the way to win was to use teamwork

Purple: k stick together. Direction: Right

Again, Free Chat3 and -4 are devoid of such language.

"Help" and "move"

While these specific words aren't used very often in any of the sessions, the idea of "working with" others and "go[ing]" left or right is a common call from Gray in Free Chat6. We include help in our 6 recruitment words as a term that could be used to recruit others, as evidenced by Brown in Free Chat1: "3 is optimal I think / HELP US PROTECT / 3 protecting". Similarly, we include move as a general purpose verb that connotes going from one place to another. Move also readily combines with together.

\section{Scavenging Words}

\section{"Harvest," "defend," and "switch"}

The two most natural candidates for the set of scavenging words are included in the rollover text when a participant right clicks on a meat source: harvest and defend. The third word, switch, appears in every session, except Free Chat4, as part of discussions on how to coordinate scavenging. These examples illustrate typical uses:

Free Chat1, period 27

Brown: when you're done just switch over

Orange: we should just get the extra / and then give it to you guys

Red: get extra and share?

Purple: yea that sounds perfect

Orange: switch with someone

Free Chat2, period 26

Pink: Should we each just get to 10 and then switch?

Brown: yep

Orange: switch

Brown: each get to ten then switch

Free Chat 3 , period 13

Green: one person defends and one harvests. then switch off on the tiger

Free Chat5, period 20

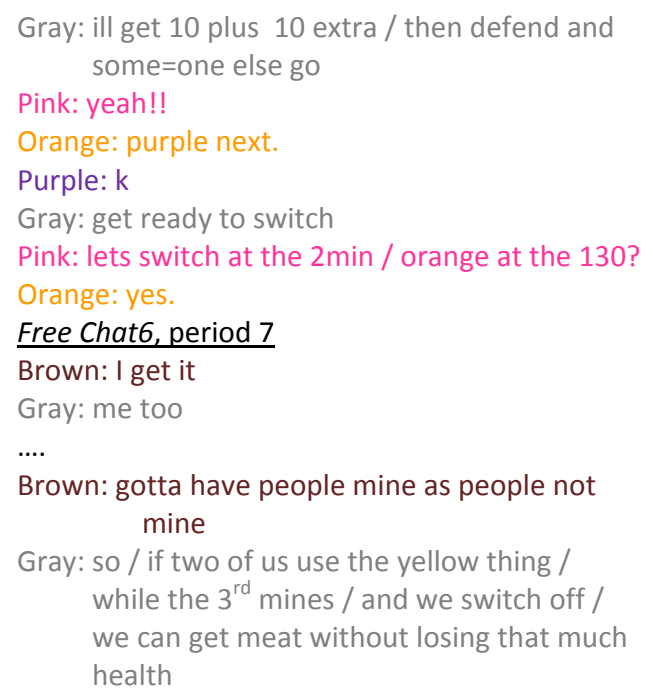

\section{The Remaining Words/Symbols}

Table 2 lists all of the words and symbols available to the participants in the Bounded $(B)$ treatment. The arrows in the \{Pointers\} set are included to accommodate gesturing in specific directions. Bowie (2008) finds that participants instinctively gesture when asked to communicate a scenario with a fifty-word vocabulary. We chose the rest of the words and symbols because they appear frequently in 
Free Chat conversations about recruitment and scavenging.

Table 2. Words and Symbols in the Bounded Treatment

\begin{tabular}{|c|c|c|c|c|c|c|c|c|}
\hline$\{\text { Recruitment }\}^{*}$ & $\{\text { Scavenging }\}^{*}$ & $\{\text { Meat }\}^{*}$ & $\{$ Substantives\} & $\{$ Exchange $\}$ & $\{$ Assent/dissent $\}$ & $\{$ Quantifiers\} & $\{$ Pointers $\}$ & $\{$ Dispositions\} \\
\hline follow & harvest & meat & 1 & give & yes & 1 & $\leftarrow$ & :) \\
\hline need & defend & & me & to & no & 2 & $\rightarrow$ & $:($ \\
\hline stay & switch & & we & & ok & 3 & $\downarrow$ & $?$ \\
\hline together & & & us & & & & $\uparrow$ & \\
\hline help & & & you & & & & $\nwarrow$ & \\
\hline \multirow[t]{2}{*}{ move } & & & people & & & & $\searrow$ & \\
\hline & & & berries & & & & ス & \\
\hline
\end{tabular}

*N.B. These words do not appear until a participant has right clicked on meat or until someone has given a participant meat.

\section{The Bounded Treatment}

Figure 7 reports the average net health gains from scavenging guarded meat in the Bounded treatment. Notice how the six sessions, as a set, replicate the results from the Free Chat baseline: One session (B2) excels in cooperating against the tigers, three others yield positive results in the second half of the session (B3-5), and two sessions perform quite poorly (B1 and B6). In other words, this is a nontrivial problem in an uncertain world. Considering that participants can only use 37 words/symbols to cooperate, the resemblance of the results is remarkable. For the remainder of this section, we explicate how participants use language in $B 2$, the most successful session, to effectuate cooperation in our scavenging problem. In the next four sections we will consult this and other narratives to gradually remove sets of words/symbols until cooperation completely collapses.

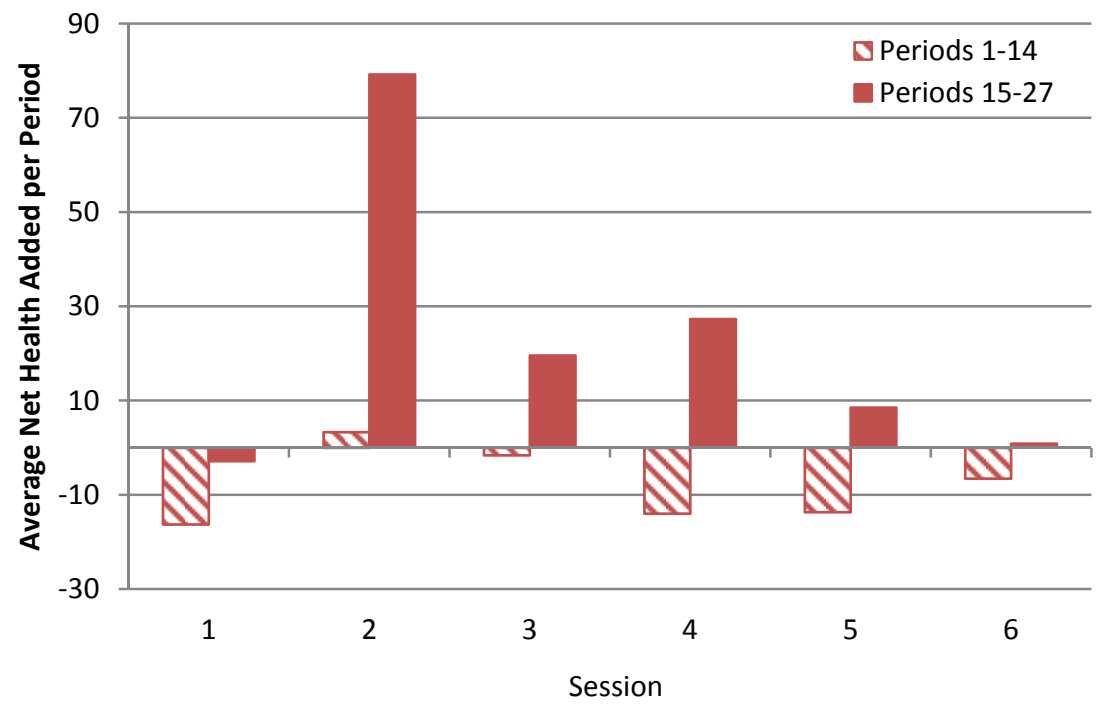

Figure 7. Bounded Results for Scavenging Guarded Meat

We observe that process of cooperation in B2 developed in three distinct stages. Participants first use language to establish meat as a common end. Then they use language to recruit additional members to form a full-sized band. Finally, participants use language to maintain the band in the face of 
competing ends and efficiently collect guarded sources of meat. A common stumbling block of the unsuccessful sessions in this and every other treatment is that the persuasion in the first stage does not work. Meat never becomes a common end.

\section{Establishing Meat as a Common End}

As night approaches in period 2, Blue and Brown meet up at the westernmost oasis. Both had just harvested from an undefended source. Before even encountering a tiger, Blue proposes they pair together. As Brown's assent makes clear, the two have the same purpose of "stay[ing] together", but Brown has an additional purpose not yet common to Blue:

Blue: stay together?

Brown: meat meat meat / move together stay together meat

For the majority of the next 8 periods, Blue proceeds to follow Brown around and power scavenge. No one else bands together until period 8; the other avatars power scavenge haphazardly as their paths happen to cross, but they rarely utter "harvest", "defend", or "switch" to coordinate their scavenging and not once do they say "together" or "stay together". Orange, Brown, and Blue power scavenge together from a tiger in period 6, but they break up immediately afterward. In period 7, Blue, Orange, Pink, Brown, and Gray power scavenge from the same tiger. They call on each other 14 consecutive times to "defend" against the tiger, but their scavenging remains uncoordinated. They break up without any calls to "stay together".

Throughout the early periods of the session, meat is evidently an end for many participants. By period 7 Blue, Brown, Purple, Gray, and Teal have all discussed meat. In period 3, Blue responds "yes" to Brown's suggestion that they "together stay... meat :)". In period 6, Gray suggests "need defend meat together" to Brown. Finally, in period 7, Purple confirms Teal's suggestion to "stay together...we defend" with "ok". The initial problem to overcome, thus, is to persuade individuals with the same end to form a band with a common end. Individuals may pursue identical ends, but those ends must be joined/united into one that is shared before it can be said that they pursue a common end.

During the night of period 8, two groups of three avatars discuss what to do the next day. Brown says to Blue and Gray "to meat". Both question Brown's end: Blue responds with "?" and Gray with "marrow ?". When day breaks, Gray heads to the gathering area alone. Meanwhile, at a separate oasis, Teal seeks agreement on his group's end, asking Red and Green whether they should "move together?" Green responds with a simple ":)". When the night ends, Blue and Brown move counterclockwise along the power scavenging path while Red, Green, and Teal move clockwise. Eventually they meet at a tiger and instantly begin scavenging. As in period 7, they spam the word "defend", but this time Brown adds "we defend you give". Green also says "follow together" while he is collecting meat, the first occurrence of such language at a tiger. The group then reconvenes at the same oasis for the night. Red, however, breaks off and goes her own way.

Meat is an end but not yet a common end. Even after benefiting greatly from scavenging guarded meat, Blue breaks off from the group in period 10. His departure leaves only Green, Brown, Teal and a new arrival, Pink, to scavenge from the tiger. While they are able to scavenge with little 
injury, Green loses the group as they seek refuge for the night, leaving only Pink, Teal, and Brown together. In period 11, Pink deserts Brown and Teal, but soon encounters Red, Gray, and Blue on their way to a tiger. Blue collects meat, but he does not reciprocate in his turn to defend. Red subsequently breaks off the group.

In the meantime, Brown and Teal find a tiger and collect some meat, but instantly agree that they lack the necessary numbers to defend against the tiger without injury. Brown says "need help" to Teal, to which Teal responds with "yes." This is the first time in the session that any participants discuss the "need" for additional participation. That same night, at a separate location, Gray, Blue, and Pink have a similar conversation about "need[ing]" another person to avoid injury ("we need 1 people"). Importantly, they no longer discuss the competing ends of berries and marrow. Despite frequent defections, meat has become a common end for five different avatars. The problem is that they are in two separate groups with insufficient numbers to avoid injury while scavenging guarded meat. The next challenge to overcome is recruiting members for a full-sized band of at least four avatars.

\section{Forming a Band}

The key question for the avatars at this stage is how to collect meat; i.e., how do "we" scavenge without getting hurt. The task is framed in terms of "need[ing] help" as Brown says to Teal and Orange, whom he had just met the night of period 11. All three head east with Brown in the lead, each keeping another avatar in their field of vision. When Teal and Brown approach the tiger they immediately start defending against it, waiting for Orange to collect meat. When Orange does so (and takes some hits from the tiger), Brown again says "need help". They switch off briefly and then as night approaches the trio heads further east to an oasis. That night Brown reiterates that they "need help" to form a full-sized band. Teal agrees: "need help / we need people".

On their way west, Brown and Teal lose Orange as they meander the world searching for people. Orange will be a loner-gatherer for the remainder of the session. At one point Teal says "people ?", but they don't see anyone. The other trio of Gray, Blue, and Pink do not discuss needing a fourth person in period 12. Having traveled all the way east, Pink proposes "stay together berries" at the dawn of period 13. The group picks up Green as they travel west to the original home base. There, they join with Brown and Teal. As soon as Brown and Teal see the others at the original home base, Brown initiates discussion to form a band:

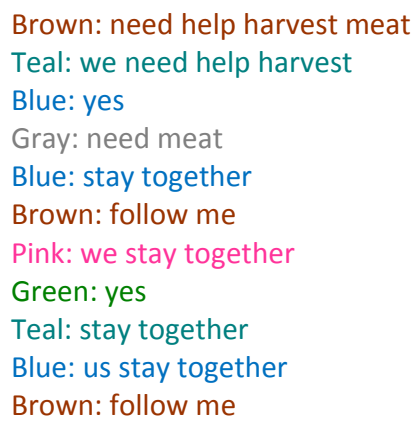

Pink: yes :)

Teal: we stay together

Gray: follow together

Green: ok

Pink: ok

Teal: :) :) :)

Brown: harvest together

Blue: :)

Pink: berries

Gray: meat meat meat :) :) :) 
out and scavenges from a tiger with maximal gain and minimal injury. That night, Brown again prioritizes the band's ends: "meat 1 berries 2 ".

When moving west during the following period, the band splinters as the avatars lose sight of each other. Brown, Gray, Green, and Purple (BGGP) maintain a full-sized band, while Pink, Blue, and Red (PBR) end up one short. Pink and Blue both propose that they "stay together". In period 22, each group finds a different tiger from which to collect meat. Not surprisingly, PBR average a net health loss of 0.68 health points. As Blue says, they "need 1 [more] people". In contrast, BGGP add an average of 12.17 net health points.

The two groups merge at the westernmost tiger in period 23, and successfully scavenge. With ample time remaining, Pink suggests " $\leftarrow$ berries" and they head further west to gather berries and camp in the original home base. At dawn, the large band flocks east and descends upon some unguarded meat. After collecting, it splits into two groups: Pink, Purple, and Red (PPR) and Blue, Brown, Gray, and Green (BBGG). PPR return in period 25 to the original home base to gather berries. At dawn on the following day, they gather berries and marrow and return to the edge of the power scavenging area to collect meat.

In the meantime, BBGG scurry further east and, that night, reinforce their common end:

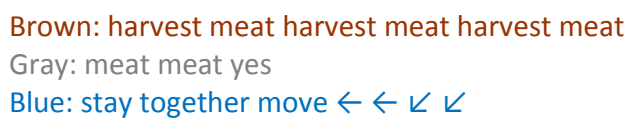

For the next two days they travel together, scavenge guarded meat, and share it. While scavenging, their conversations focus on the efficiency with which they collect meat:

$\begin{array}{ll}\text { Period } 25 & \text { Blue: I harvest } \\ \text { Green: switch yes ? } & \text { Gray: switch } \\ \text { Gray: stay } & \text { Brown: switch } \\ \text { Brown: switch } & \text { Blue: switch switch switch } \\ \text { Blue: switch switch switch } & \text { Gray: move move } \\ \text { Gray: } 3 \text { defend / switch switch } & \text { Brown: no meat :( } \\ \text { Period } 26 & \text { Green: meat meat meat /:) } \\ \text { Brown: } 3 \text { defend } & \end{array}$

Curiously, the band appears indifferent to free-riding. In period $25 \mathrm{Teal}$, who has been a lone wolf since the great breakup of period 21, comes across BBGG defending guarded meat. She collects 10.5 units of meat and continues on her merry lonely way. BBGG neither objects nor attempts to recruit her to the band. The next day, Teal is the first to approach a tiger. When PPR appears, she calls "defend defend defend". PPR obliges, and when Teal collects her 11.3 units, she splits again. ${ }^{7}$

In period 27, BBGG head west and run into PPR, which is traveling east. PPR changes direction and flocks with BBGG as one large group to scavenge guarded meat (one last time) unbeknownst to them. Each avatar collects as much meat as he or she can and then retires at the same oasis for the

\footnotetext{
7 PPR have a total of 14.7 units of meat between the three of them. That night Purple, who has 13 units of meat, exchanges 5 of those more valuable units with Pink and Red for inferior marrow and berries.
} 
night. Pink suggests "us berries stay together $\leftarrow$ ", but Brown says "berries no meat yes :)". Gray echoes Brown, saying "no berries meat yes", as does Blue who says "no berries meat yes". The combined groups are poised again to go their separate ways. Brown speaks for BBGG when he says, "meat $\uparrow$ [thumb up] berries $\downarrow$ [thumb down]".

\section{The Bounded-\{Recruitment $\}$ Treatment}

Given the prominence of recruitment in Bickerton's hypothesis, and of recruitment words in B2, for our next treatment condition we exclude the 6 recruitment words in the first column of Table 2 . This is the sole difference between $B$ and this Bounded $-\{$ Recruitment $\}(B-R)$ treatment.

Figure 8 reports the results by session for this treatment. Notice again that one successful session $(B-R 4)$ stands apart from the rest, and that two other sessions find a little success $(B-R 1$ and $B-$ R2). The other three sessions find no success. We again present a narrative of the most successful session, with the aim of removing another set of words in the next treatment condition.

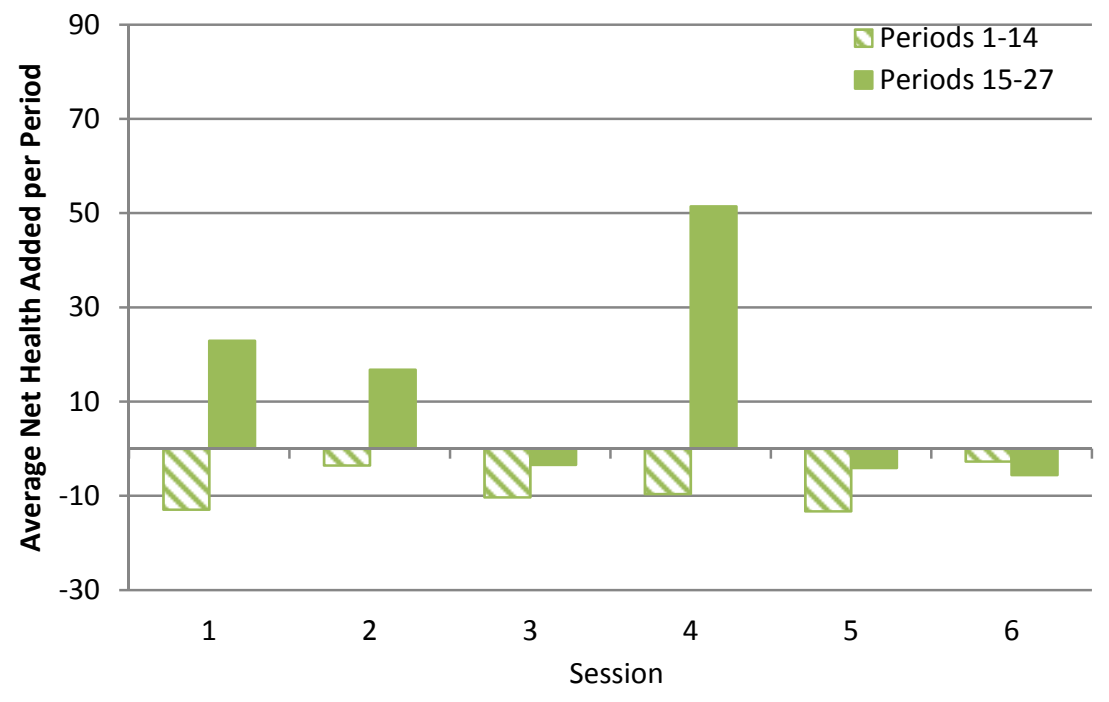

Figure 8. Bounded - $\{$ Recruitment $\}$ Results for Scavenging Guarded Meat

The process of achieving success in B-R4 follows a pattern similar to the one we observed in $B 2$. The participants begin by defining the goal. They then move on to forming the band and working to ensure the band stays together. The important distinction is this treatment is how the band forms. While the band in $B 2$ grew partly through active recruitment, i.e., participants sought others and persuaded them to power scavenge, the band in $B-R 4$ grows almost exclusively through common experience with power scavenging and through happenstance encounters at night.

\section{Establishing Meat as a Common End}

Until period 16, the avatars move haphazardly around the world, gathering marrow and berries and occasionally scavenging for meat. Meat slowly becomes an end for many of them in these early periods. The first suggestion to scavenge for meat comes in the night of period 3, when Brown, Gray, and Blue gather at the home base oasis: 
Brown: $\rightarrow$ harvest $/ \leftarrow$ berries

Gray:?

Brown: $\rightarrow$ harvest $\leftarrow$ berries

Blue: $\leftarrow \rightarrow \rightarrow \leftarrow \leftarrow$

Gray: yes

Brown's early suggestion to " $\rightarrow$ harvest" falls on deaf ears, for on the morning of period 4, neither Blue nor Gray follow him into the power scavenging area. They gather berries instead, but later move into the power scavenging area.

In period 5, we observe language that begins to shift from vague notions of power scavenging toward power scavenging at specific locations:

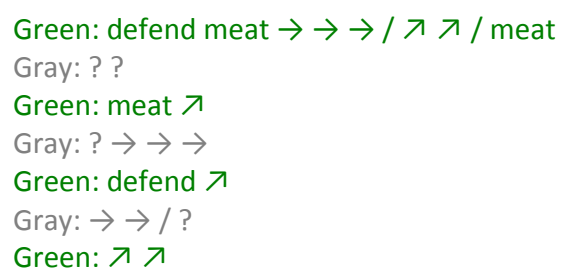

This language is unsuccessful in generating a power scavenging band, as Gray and Green break up after briefly scavenging meat. However, it does set the stage for further uses of pointing to establish meat as a common end. The next instance of location pointing occurs in period 8. Having scavenged from the same tiger, Green, Pink, and Red move to an oasis together and find Brown there. They immediately begin discussing power scavenging:

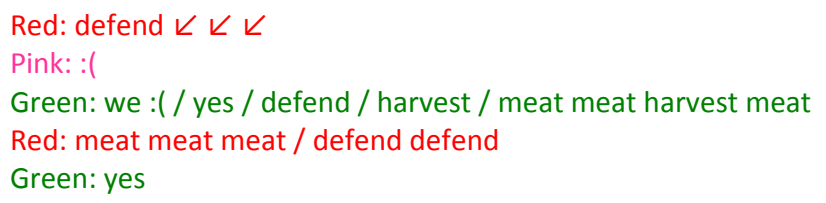

Note that both of these conversations contrast with the language seen in B2. While participants in $B 2$ used language such as "stay together harvest defend meat" and "follow me" to direct avatars' movements, participants in B-R4 might state "defend harvest meat" because "follow me" is not available. Pointing toward a commonly understood end also appears to effectively replace the use of "stay together" and "follow me."

Another exemplar attempt at directing others to pursue meat occurs in the night of period 13, when Blue, Purple, and Red are together:

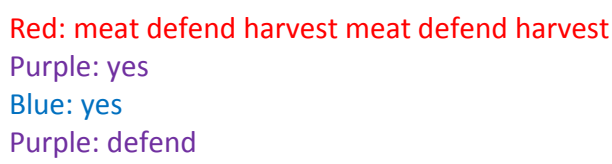

Again, in the night of period 14, when Red and Purple are together:

Purple: defend harvest defend harvest defend harvest / yes :)

Red: yes 
By the end of period 16 Blue, Brown, Green, Gray, and Purple, Red have all either used language suggesting meat as a goal, or have explicitly confirmed meat as a goal.

\section{Forming a Band}

Frequently, the participants opportunistically scavenge in temporary groups, and coordinate their power scavenging efforts using "defend" and "harvest". Occasionally, they directly ask others for "meat". However, it is not until period 17 that an enduring power scavenging band begins to form. Concurrent with the formation of a band, there is a fundamental shift in how participants discuss power scavenging-from pointing in the direction of meat, to, eventually, identifying as "meat people." The first instance of "we" being used in the same phrase as power scavenging marks the beginning of this shift: ${ }^{8}$

\section{Brown: we $\rightarrow$ meat / we defend meat}

Red: yes

In the morning, Red and Brown move together as a group, maintaining sight of each other until they find Purple and Gray scavenging guarded meat. Gray leaves the group before nightfall, but Teal soon joins Red, Brown, and Purple at an oasis. Once again, they attempt to solidify the band, as Brown and Red again make use of the word we:

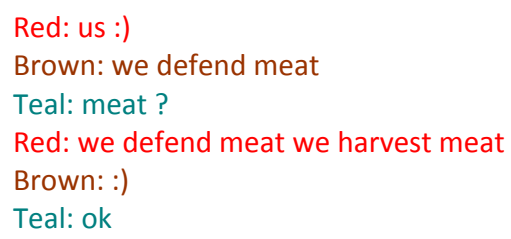

Red, Brown, Purple, and Teal move back to the same tiger in period 19 and scavenge. They only achieve an average net health added of 3.47 (15.70 gained, 12.23 lost), and the band breaks up. Purple follows Red to one oasis and Brown and Teal move to another. Finding Orange, Teal invokes "we" in an attempt to form a band:

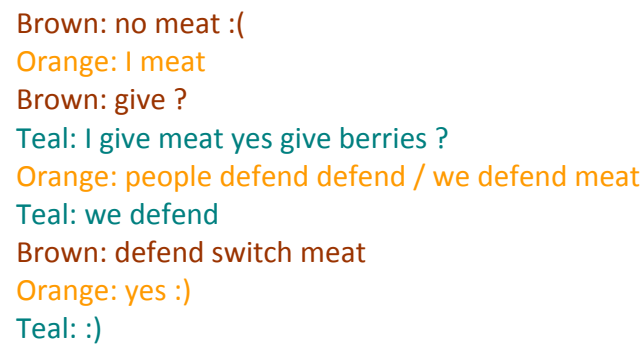

In period 20, the group of Brown, Orange, and Teal walk along the path, never letting another member out of their sight. They find some unguarded meat and scavenge together. Teal then breaks off from the group; Brown and Orange move together to an oasis for the night.

\footnotetext{
8 "We" had previously been used only one other time in the session (aside from chat spam) when Pink lamented "we :(" after a poor scavenge in period 5 .
} 
Brown, Gray, Orange, Pink, Red, and Teal, (BGOPRT) go the other. That night, the band discusses their plan:

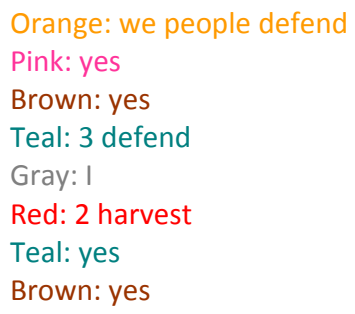

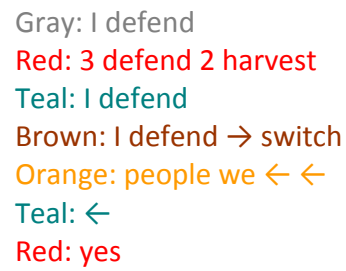

Importantly, throughout all of these periods, no one actively recruits others to form a band. A scavenging band eventually forms through a slow and gradual process of happenstance encounters.

\section{Maintaining the Band}

In the morning of period 24, BGOPRT moves out and reunites with Blue. They then find a tiger and scavenge. Red leaves the group but Purple, with some luck, finds it and joins. The eight avatars achieve an average net health gain of 12.20 (18.00 gained, 5.80 lost). Now constituted as BBGOPPT, the band retires to an oasis for the night. Teal describes themselves as "we meat people". In the morning, BBGOPPT rushes out as a herd and chances upon Red, whom they join in scavenging some unguarded meat. When they finish, Purple and Orange each go their own way and the rest of the band moves towards the gathering area. They settle at an oasis where Teal attempts to maintain the band by repeating "we meat people".

During the night of period 25 Blue, Brown, Gray, Pink, Red, and Teal are together at an oasis. So close to the gathering area, several people introduce competing goals for the band, asking "berries ?" and "marrow ?". Red is the only participant to discuss the group's goals with an emphatic "berries $\downarrow$ $\downarrow$ " for pursuing berries and a corresponding "meat $\uparrow \uparrow \uparrow "$ for pursuing meat. Recall that Brown, in periods 26 and 27 of B2, similarly said: "meat $\uparrow$ berries $\downarrow$ ". Red and B2's Brown are persuading their groups' constituents to continue their cooperation.

On the morning of period 26, Blue, Brown, Gray, Pink, Red, and Teal initially move out from the oasis in two separate groups, but soon gather themselves and flock like birds along the path. Each avatar remains visible to their two nearest band members, one in front and one behind. The band, rejoined by Orange and Purple along the way, swoops down find and engage a tiger. They add an average net health of 10.30 health points (14.65 gained, 4.35 lost).

Reconstituted as BBGOPPRT, the eight-member band heads to the same oasis for the night and continues to describe themselves as "meat people":

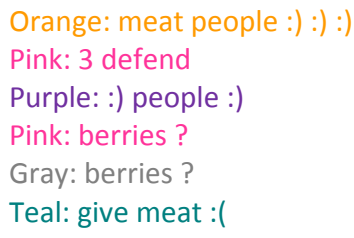

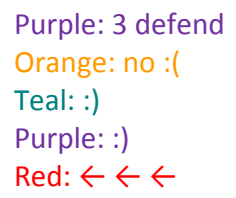


Following Red's suggestion, BBGOPPRT flocks westward from the oasis, and eventually descends upon a tiger. They gain an average net health of 16.33 health points (17.42 gained, 1.09 lost). Upon moving to an oasis for the final night, Orange continues to refer to the group as "meat people":

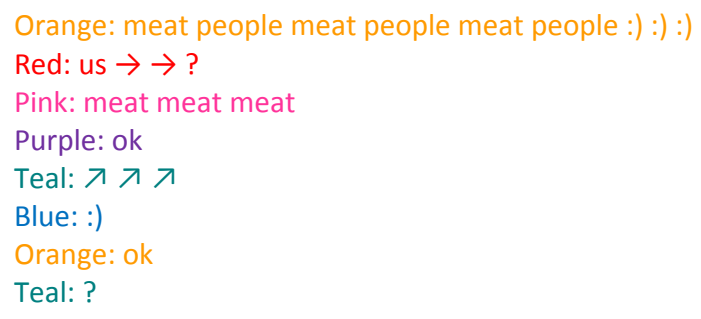

\section{The Bounded $-\{$ Recruitment $\}-\{$ Scavenging $\}$ Treatment}

When participants in $B-R$ cannot use recruitment words, they fall back on the scavenging words in column 2 of Table 2. In our next treatment condition, we remove the scavenging words harvest, defend, and switch from those available. This is the sole difference between the $B-R$ treatment and what we will call Bounded-\{Recruitment $\}-\{$ Scavenging $\}(B-R S)$.

Figure 9 reports the results from the treatment by session. Notice that, for a fourth time, one successful session ( $B-R S 3$ ) stands apart from all the rest, and that two other sessions ( $B-R S 2$ and $B-R S 4)$ find modest success. The other three sessions find little or no success. We again present a narrative of the most successful session with the aim of removing another set of words in the next treatment condition.

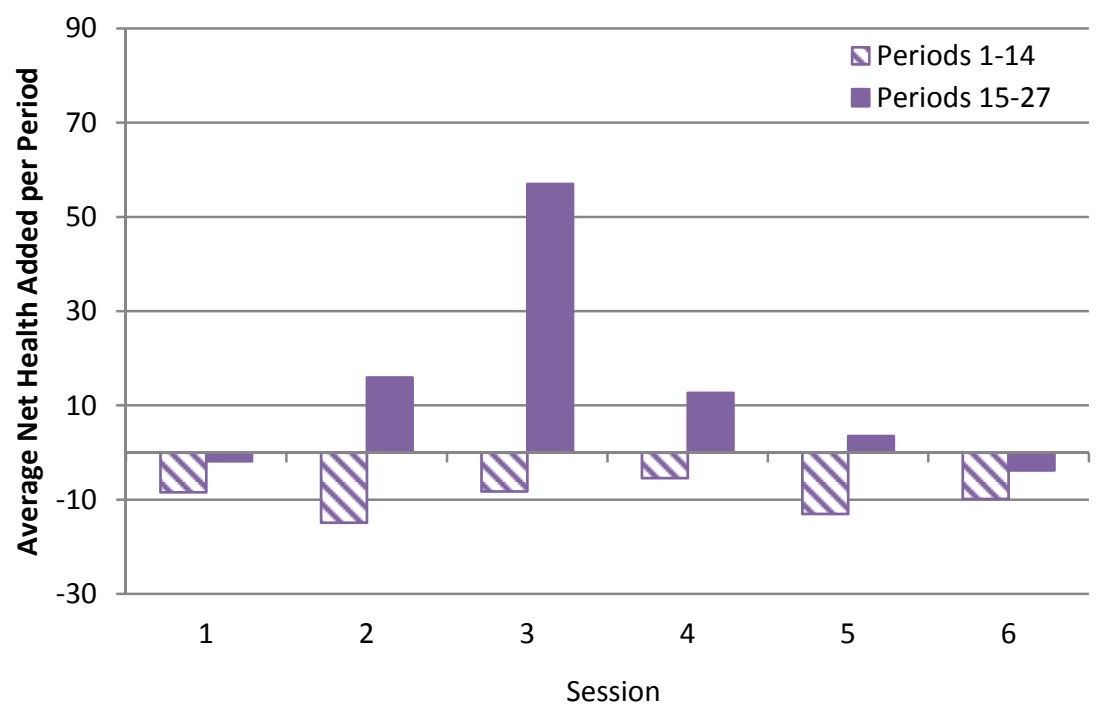

Figure 9. Bounded - \{Recruitment $\}-\{$ Scavenging $\}$ Results for Scavenging Guarded Meat

$B-R S 3$ follows the same broad patterns of success as those in $B 2$ and $B-R 4$. With the exclusion of the scavenging words, however, the participants in the $B-R S$ treatment must change how they form and maintain a scavenging band. More so than $B-R 4$, they rely on the directional arrows to establish 
meat as a goal, and the participants attempt to maintain their bands by identifying the constituents as "meat people."

\section{Establishing Meat as a Common End}

The session begins uneventfully, much like $B 2$ and $B-R 4$. Until period 6 , the avatars haphazardly move around the world collecting marrow and berries and occasionally scavenging for meat. At the beginning of period 6, Gray scavenges from a tiger by himself at a net cost of -11.00 (9.00 gained, 20.00 lost) to his health. As he travels west along the path he encounters Green travelling east. Gray quickly says " $\rightarrow$ / meat / meat / $\rightarrow$ we" to Green, which is the first time that the word meat is used in the session. Gray and Green then move eastward together along the path and soon are scavenging guarded. Because it is late in the day, they break off quickly and head back to an oasis. During the night, Gray suggests that they need another group member. In $B 2$ and $B-R 4$, avatars could say "2 defend 1 harvest meat". But in the $B-R S$ treatment, Gray does not have the words switch, harvest, or defend available to him; instead, he says "no[,] 2 yes 1 meat / us".

Gray's attempt to establish meat ("meat/us") as a common end is for naught as Gray and Green part ways the next morning. Gray continues his movement around the power scavenging area, eventually encountering Red at an oasis nearby a tiger. With the utterance "we / meat $\rightarrow$ " Gray attempts to establish meat as a common end with Red. Red follows Gray to the tiger and Green soon arrives and joins them. Because it is very late in the day, they scavenge briefly and then move together to a nearby oasis. During the night, they don't talk except for a couple of short utterances by Gray.

The next morning the trio heads back to the tiger and average a net health loss of 4.41 (14.46 gained, 18.87 lost). Gray attempts to coordinate their scavenge using the limited language available: "no / 1 / yes yes". Red, however, doesn't understand, and replies "? ? ?".

Purple swoops in briefly to scavenge, but the group doesn't last. Red and Green move off to an oasis, and Purple and Gray soon go their separate ways. During the night of period 8, Red briefly asks Green whether meat is a common end: "you :) meat ? / I ? meat". The next morning Red and Green quickly break up. When Red meets Purple on the path, Purple immediately says "meat". They travel together to some unguarded meat, scavenge, and head back to an oasis for the night. The night continues to be uneventful as Purple simply says "meat" to Red.

The next day, Red and Purple find a tiger. As they begin to scavenge from it, Gray shows up to join them. After the three of them lose an average of 2.35 health points (10.62 gained, 12.97 lost), Gray leaves the group. That night, all Purple says to Red is "meat", which doesn't appear to be compelling, as they break up the next morning.

Later, Gray comes across Teal and directs him “ $\nearrow$ meat" to a tiger he had just seen. Teal follows Gray to the tiger and Purple quickly joins. While Purple and Gray scavenge from a tiger, Teal watches from a short distance. As night approaches, the group again breaks up. Without the recruiting and scavenging words, meat is not yet a common end for any subset of the nine avatars. 


\section{Forming the Band}

The next instance of grouping occurs in period 13, when Gray meets Green on the scavenging path. Gray says to Green " $\rightarrow$ meat / $\rightarrow \rightarrow \rightarrow$ ". However, they do not find any and lament "no meat ? : / / no meat :(" as they continue along the path. That night, Gray suggests "meat $\rightarrow \rightarrow /:($ / meat 3 people". Notice that Gray is communicating a need for an additional avatar without the word need. This is the first time that such language occurs in the session.

In period 14 Gray and Green set off together, presumably in search of a tiger. Finding one, they scavenge from it, losing on average 1.75 health points (9.45 gained, 11.20 lost). Gray continues to discuss "3 people": "meat 3 people / yes / people 3". They then move to an oasis for the night and continue discussing the need for more people:

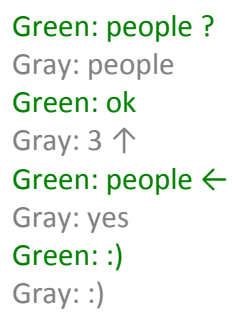

Moving together in period 15, Gray and Green eventually stumble across Purple and Teal at a tiger. Orange soon encounters the group and the five avatars scavenge for an average net health gain of 5.93 health points (11.27 gained, 5.34 lost). Before dusk, Orange leaves, while Gray, Green, Purple, and Teal congregate together at an oasis. Gray sums up the day saying, "meat ok".

In period 16, Gray, Green, Teal, and Purple travel along the power scavenging path until they approach the westernmost oasis. As the group moves toward the gathering area and off the power scavenging path, Gray points " $\nearrow$ "back toward the scavenging area. Green and Teal immediately change their direction and continue to follow the scavenging path. They are quickly followed by Purple. Teal soon loses the group, leaving Gray, Green, and Purple to go their own way and collect some unguarded meat. They move together to an oasis for the night where they are joined by Red. That night, Gray, Green, Purple, and Red discuss moving towards meat:

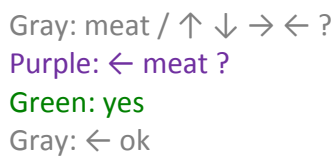

The night of period 16 marks the formation of a band comprised of Gray, Green, Purple, and Red (GGPR). The band's formation during this period reflects the past histories of the four avatars, and their shared experience with power scavenging. Prior to the night of period 16, Gray and Green had scavenged together for the previous three periods; Gray, Green, and Purple had scavenged together in the previous two. Furthermore, Gray and Green had discussed the need for more avatars in period 14 when Gray said "meat 3 people / yes / people 3". Additionally, Red, Purple, Green, and Gray had extensive histories even prior to period 13: Gray and Green had power scavenged together in period 6; Gray, Green, and Red in period 7 and 8; Red and Purple in period 10; and Gray and Purple in period 11. 


\section{Maintaining the Band}

In period 17, GGPR moves along the scavenging path and finds some unguarded meat. They quickly scavenge and continue moving, gathering marrow along the power scavenging path. Red falls behind picking up marrow and loses the group. Gray, Green, and Purple move to an oasis for the night. Interestingly, Gray discusses meat but none of the other members of GGPR discuss Red's absence:

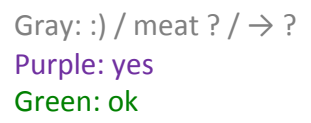

In period 18, Gray, Green, and Purple move out and find a tiger. They begin scavenging and Red soon rejoins the group. Reunited, GGPR adds an average net health of 6.43 health points (9.41 gained, 2.98 lost) and will remain together for the remainder of the session. The band then moves to an oasis for the night. There is little discussion of movement aside from Gray suggesting " $\leftarrow$ ?", to which no one responds. Nevertheless, the next day the band moves along the path, finds a tiger, and adds on average net health of 14.37 (18 gained, 3.63 lost). This was a substantial improvement over the previous period. Before they retire to an oasis, Gray says "me $\searrow$ " to inform the group of his planned movement. Gray is careful that the other avatars see him.

In the morning of period 20, GGPR moves off in the direction they decided the night before

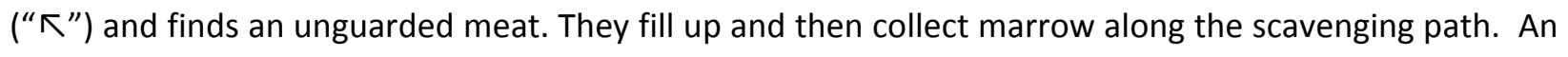
important feature of this period, and periods 22 and 26, is that the band remains together after finding unguarded meat. This is an important difference between this session and $B 2$ and $B-R 4$. In the other sessions, the bands frequently break up when there is no tiger (period 20 in $B-R 4$ and period 21 in B2). The persuasion in these sessions in these sessions fails to dissuade others from pursuing competing ends, like gathering berries and marrow.

Another notable distinction of $B-R S 3$ is the deference and concern the participants display to each other. During the night of period 20, Gray suggests going west while Red suggests the opposite direction:

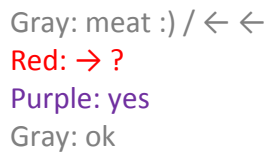

Up until this point, Gray has been the leader of the band. But Gray defers here and the band goes with Red's suggested direction. This sort of behavior is largely absent from B2 and B-R4. Gray also waits by the meat to ensure that the other avatars proceed to the same oasis, clearly indicating to which oasis he is headed ("me $\searrow$ "). We speculate that Gray is concerned that the band will break up without access to the words stay together. Throughout the session the participants maintain the band by agreeing which direction to travel. In period 21, the band adds an average net health of 17.27 health points (18 gained, 0.73 lost).

The only addition to the GGPR band comes with Teal, who joins in period 22. He comes across the band as they travel along the scavenging path and begins to move with them. Interestingly no one 
says anything. The band, now consisting of Gray, Green, Red, Purple, and Teal (GGRPT), just keeps going. They find some unguarded meat, and, of course, after taking full advantage of it, the band remains unified.

GGPRT continues to power scavenge successfully throughout the remainder of the session. In periods 23-27, they add an average net health of 15.09 health points (per tiger encounter) across all five of these periods (16.65 gained, 1.56 lost). The language in periods 23-27 is very similar to language in period 18-22. They continue to discuss "meat" using directional arrows and extensively affirm one another with smiles. One observation of note is that, during the night of period 24, Gray identifies the band as "meat people":

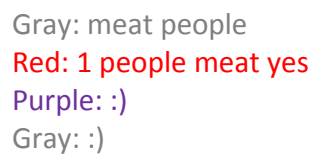

"Meat people" is a phrase we observed in B-R4, but it is notably absent in B2. Participants in the Bounded treatment can be more direct with "stay together meat" and "follow meat". Without access to these phrases in the $B-R$ and $B-R S$ treatments, the participants need a different way to encourage cohesion. The phrase "meat people" is one way to overcome the language restriction by encouraging cohesion through ensuring that meat is a common end for each member of the band, rather than by "stay together" directives. As their common end, meat becomes an identity.

The band formation process in $B-R S 3$ reflects the limited language options that participants have. By pointing and using meat, they slowly build a stable band from the same individual experiences they each have with scavenging.

\section{The Bounded $-\{$ Recruitment $\}-\{$ Scavenging $\}-\{$ Meat $\}$ Treatment}

When participants in $B-R S$ could not use recruitment words, they relied heavily on the word meat as both a verb and an object. In our next treatment condition, we remove that one word-meatfrom the list of available words/symbols. This is the sole difference between the $B-R S$ treatment and what we will call the Bounded $-\{$ Recruitment $\}-\{$ Scavenging $\}-\{$ Meat $\}(B-R S M)$ treatment.

Figure 10 reports the results from this treatment by session. Notice for a fifth time that one session (B-RSM2) stands apart from all the rest. In this treatment, however, the distinction is considerably less than that of the best performances of the previous treatments. We have come a long way towards eliminating the words that the participants use to solve the scavenging problem. By removing the word for the common end, meat, we substantially stunt the ability of our participants to band together and scavenge. Nevertheless, one group of four participants eventually makes it work. We again present a narrative of the most successful session, for it continues to explicate the process we have observed in the previous treatments. Success, though, comes here with much greater difficulty.

Participants in $B-R S M 2$ go through a different process for forming a band than those in $B 2, B-$ $R 4$, and $B-R S 3$. Because they lack access to the word meat in this treatment, the participants cannot readily establish meat as a common end by directly referencing that end. Individuals must discover, on 
their own, that (a) meat generates more calories than berries, and that (b) four avatars are needed to scavenge guarded meat without harm. Further, because they cannot use meat in conjunction with arrows to direct uniform pursuit of the common end, the participants must rely extensively on we, us, and people to persuade others to both form and maintain a band.

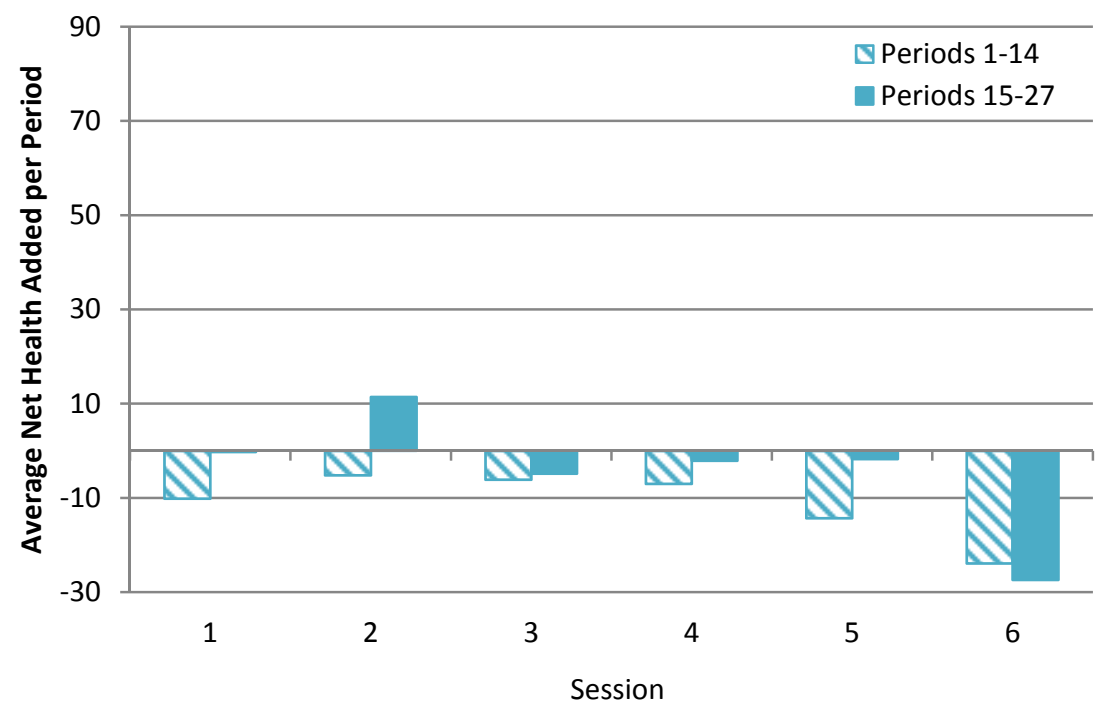

Figure 10. Bounded $-\{$ Recruitment $\}-\{$ Scavenging $\}-\{$ Meat $\}$ Results for Scavenging Guarded Meat

\section{Forming the Band}

Without the ability to directly convey the word meat, some participants realize the benefits of grouping early on while others recognize much later, if at all. The first attempt to form a group occurs in period 5, when Brown says "people / people" as he scavenges from a tiger with Orange and Pink. The three avatars, however, break up after briefly power scavenging together. They lose an average net health of 2.56 (6.54 gained, 9.10 lost).

The next use of language related to grouping is during the night of period 6, when Orange and Purple find themselves together at the home base oasis. They discuss berries, marrow, and later, us, we, and people:

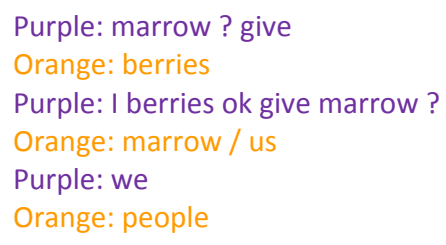

But they break up during the next period. These early uses of we, us, and people differ from the usages in $B-R 4$ and $B-R S 3$, where these words are not used until much later (in periods 17 and period 24 , respectively).

Much like $B-R 4$ and $B-R S 3$, the participants use the arrows to recruit others to scavenge. However, unlike the other two treatments, this pointing is not effective until after the band forms. This 
may reflect the inability to express meat as the objective. The first use of an arrow is in period 7, when Brown and Red are travelling west along the upper portion of the power scavenging path. Red, who had encountered a tiger to the east earlier in the period, now suggests to Brown "us $\rightarrow$ / ok ?", pointing in that direction. Brown responds "berries". They then break up without scavenging, and Brown moves to the gathering area.

In period 8, while Pink scavenges from a tiger, he sees Green passing and attempts to get Green's attention with a simple "people". Green, however, does not respond and continues along the path. That night, Green and Pink gather at an oasis; Green will eventually join the band that forms, while Pink will not. Pink points back in the direction of the guarded meat that he had scavenged:

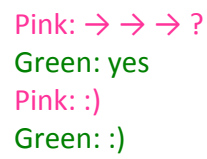

This is the first instance of sharing a smile during a conversation about scavenging. Smiling will become influential after the formation of the band. Here it is not, for Green and Pink break up the next morning. Without a group there is perhaps nothing to affirm by smiling.

The avatars continue to move haphazardly around the world. In period 9, Green, Red, and Orange find themselves at an oasis and discuss grouping:

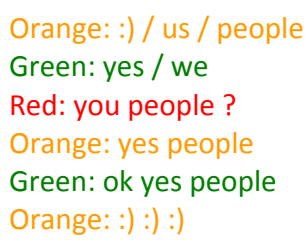

For the next two periods they scavenge together without success. They break up on the morning of period 11.

The next futile attempt at forming a band is in period 12. Red passes a tiger along the path and then happens upon Purple and Blue at the westernmost oasis. Red then attempts to recruit them to scavenge the guarded meat:

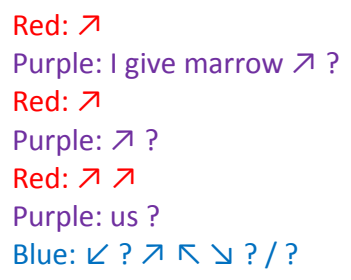

Three times, Red moves toward the tiger and then returns when Purple and Blue don't follow. Red's pointing toward the meat is futile because it's not accompanied by any expression of a common end. Once again, during the night of period 12 , Red points toward the meat: 
Purple: $\nearrow$ ok

Red: $\nearrow$ us yes?

And once again, Red's pointing is unheeded, even after Purple confirms it. Blue and Purple move to the gathering area in the morning of period 13, while Red circles around the tiger, hoping that someone passes by. Eventually, Red gives up and returns to the original home base.

In period 14 Brown, Purple, Red, and Teal converge on the same tiger and lose an average net health of 2.13 ( 6.30 gained, 8.43 lost). They then move to an oasis for the night and point where they should go in the morning:

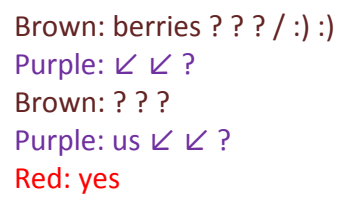

The next morning they move back to the tiger. Brown, Purple, and Red begin scavenging but Purple remains on the sidelines. Orange then comes across the group of four and joins. Brown says "us" but the five avatars soon break up completely. Excluding Purple, who does not harvest or defend, the other four avatars lose on average only 0.36 health units (9.14 gained, 9.50 lost).

In the night of period 15, Red, Purple, Pink, Orange, and Green find themselves together (they are all visible to each other) in the home base oasis. Once again someone attempts to form a band with the single word us:

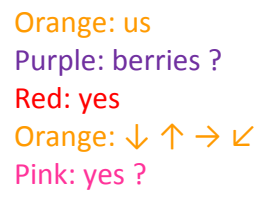

For the next 4 periods, Brown, Green, Orange, Pink, Purple, and Teal, will scavenge in various groups of two and three, but a band does not form. However, the seeds of an eventual band are planted in period 20, when Teal and Orange meet at a tiger. As they scavenge, Teal says "people" and they retreat from the tiger. Teal goes to a nearby oasis and encounters Brown. Teal points " $\rightarrow$ " to the location of the tiger. Brown follows him to the tiger, but Orange splits. Teal then goes back to the oasis to find Orange and Green, and once again he points toward the tiger. This time the recruitment is successful and Orange and Green go with Teal to the tiger. But alas, it is late in the period and they are forced to retire to a nearby oasis for the night. That night Brown, Green, Orange, and Teal discuss returning to the tiger:

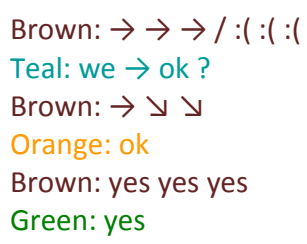


The next morning they move to the tiger and finally achieve a positive net gain of 2.81 health points (8.91 gained, 6.10 lost). The group is fragile, particularly because Green does not consistently defend. When Orange and Brown break off, Teal says "3 people," but then he leaves as well. Green, Orange, and Teal spend the night at the same oasis, and attempt to form a group and return to the tiger:

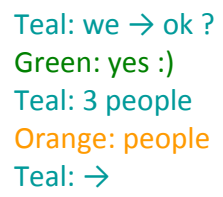

In the morning of period 22, Green, Orange, and Teal move back to the tiger and add an average net health of 1.43 (11.10 gained, 9.67 lost). The core of a band finally coalesces, late in the period, when Teal says " $\leftarrow$ " and Green and Orange follow him west to the oasis.

That night Green, Orange, and Teal meet Red at the oasis and immediately talk using we, us, people, and which direction to go the next day:

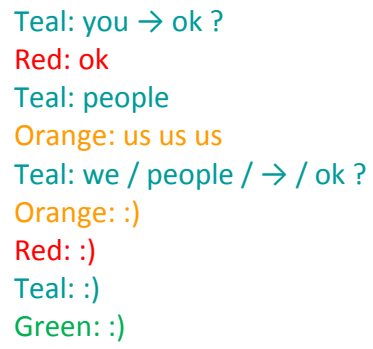

Recall that Orange, Green, and Red were the first avatars to extensively use we, us, and people in period 9. A full-sized band of Green, Orange, Red, and Teal (GORT) has finally formed and will stay togetherthough still unable to say "stay together" - for the rest of the session.

\section{Maintaining the Band}

In the morning of period 23, GORT flocks out of the oasis and descends upon some unguarded meat. Pleased with the formation, Orange says ":) :) :) / we us we" while the group scavenges. When GORT moves to an oasis for the night, the band continues building the team spirit:

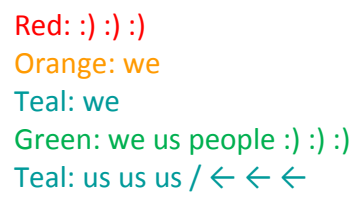

At this point in $B-R 4$ and $B-R S 3$, participants would call themselves "meat people" and perhaps thrice smile. Without recourse to meat, however, Green says the next best thing: "we us people :) :) :)".

With a stable band, then next step is to better coordinate their scavenging. Whereas, in other treatments, participants say " 3 defend 1 harvest" or " 3 meat 1 meat", Teal says " 3 people / 1 people / 3 people 1 people" and " 3 people 1 people / 3 people 1 people / :) yes". 
The scavenging pays off in period 25, when GORT adds an average of 14.79 health points (16.97 gained, 2.18 lost). That night, the discussion is very similar to that of the past three periods, though now it rings with the repetition of a feel-good cheer:

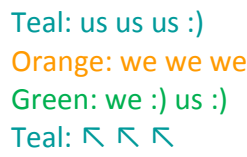

In periods 26 and 27, GORT will collect 8.89 (13.32 gained, 4.43 lost) and 17.55 (17.55 gained, 0.00 lost) health points, respectively, from scavenging guarded sources of meat. It took a long while for the band to form, but once it does, it is as successful as the most successful scavenging bands in $B$ and $B$ $R$.

In $B-R S M 2$, a tight-knit band forms, similar to the one in $B-R S 3$. However, whereas the band in $B-R S 3$ forms in period 18 , it takes until period 22 for it to form without the word meat. The average net health added from scavenging guarded meat is comparable for the two bands (11.79 in $B-R S M 2$ versus 12.41 in $B-R S 3)$.

\section{The $\{$ Pointers $\}+\{$ Dispositions $\}$ Treatment}

With the elimination of a single word, the $B-R S M$ treatment very nearly eliminated cooperation. The words we, us, and people functioned to create a common identity for the purpose of pursuing a common, concrete end. For our final treatment condition, we test whether the lack of any words stymies cooperation altogether. In what we will call the $\{$ Pointers $\}+\{$ Dispositions $\}(P+D)$ treatment, only the pointing and disposition symbols in the last two columns of Table 2 are available to the participants.

Figure 11 reports the results of the $P+D$ treatment, by session. This treatment condition plainly demonstrates that when no words are available, it is not possible to solve the scavenging problem.

Participants in every session are unable to successfully form a band, even though they frequently attempt to recruit each other to solve the power scavenging problem. In each session, when participants find others at an oasis, they suggest traveling along the power scavenging path together. Occasionally, there are also recruitment attempts while scavenging. In period 24 of $P+D 1$, for example, Gray and Orange see Brown as they scavenge from a tiger. Orange stops scavenging and moves with Brown. Orange says " $\$ ", pointing back to the tiger, but Brown does not respond and soon leaves. Also indicating their desire to form a band, participants frequently use the frown emoticon ":(" when others leave their groups.

The arrows, and emoticon usage thus seems to indicate that the participants are constrained by a lack of language. Since participants cannot discuss meat, and have no way to communicatively identify themselves or others with that objective, they are not able to form a band with the commonly held end. Their only option is to direct other avatars at night and hope they follow them to a tiger in the morning. That is not compelling enough, as the participants do not follow those directions and instead go their own way. Meat never becomes a common end. 


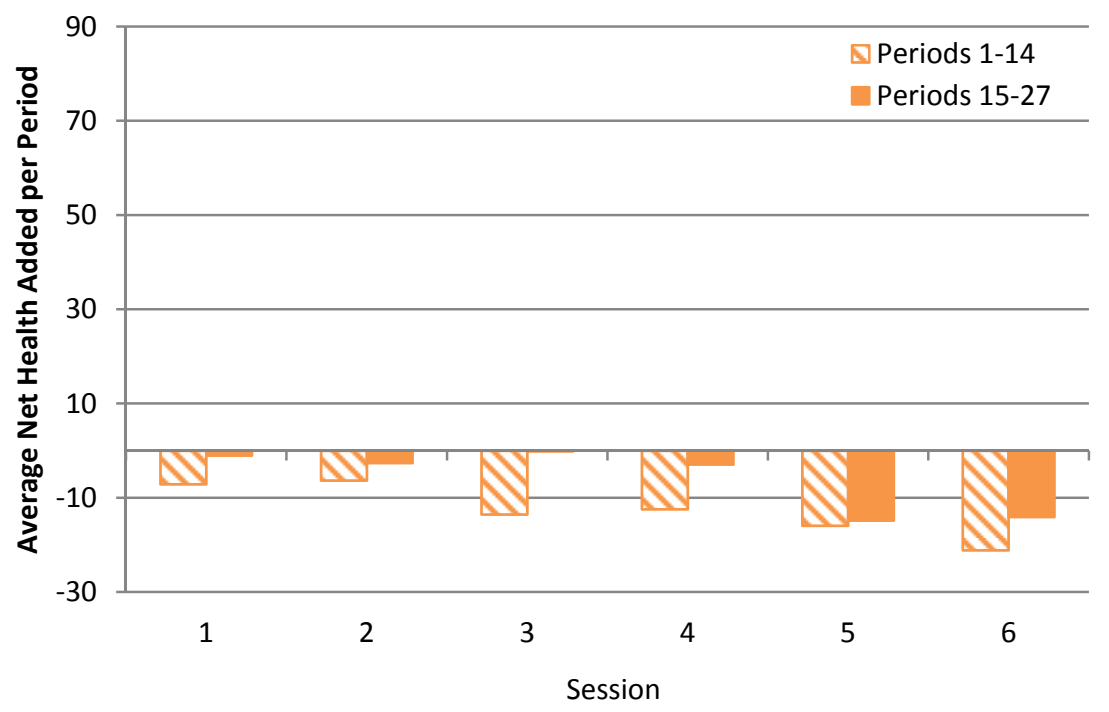

Figure 11. $\{$ Pointers $\}+\{$ Dispositions $\}$ Results for Scavenging Guarded Meat

\section{Discussion and Conclusion}

The first take away from comparing our treatment conditions is that our scavenging problem is a tough problem to solve (see Figures 6-11). It is important to recognize that the results didn't have to turn out this way. The problem could have been so easy that every session solved it, or so difficult that it was never solved. Instead, we have a severe test of our participants' cooperative powers: Only one session in each treatment regularly solves the problem. In these successful sessions, the togetherness denoted by the co- in cooperate rests on a common end. ${ }^{9}$ The environment of our virtual terrarium barely supports mere subsistence if everyone gathers their own private tokens for their own needs. To improve their wellbeing, participants in the successful sessions use language to persuade their non-kin to work together for a common end.

Furthermore, the $P+D$ treatment shows that some language is necessary to solve the scavenging problem. Although the $B-R S M$ treatment shows that it is possible to solve the scavenging problem without expressly identifying the common end, only 4 of the 54 participants in that entire treatment form a band (even there, the banding process takes 23 periods).

What insights do these treatments yield on the use of language to cooperate on a common end? First, compare the distribution of words in $B-R S 3$ and $B-R S M 2$ (see Figure 12). The single word meat is a sizable $9.2 \%$ of the words and symbols used in $B-R S 3$. This is not uncommon for the treatment. The less successful, and utterly unsuccessful, sessions in the treatment use it on average $9.8 \%$ of the time. ${ }^{10}$ In $B-R S M 2$, where meat is not available, the participants devote that portion of word usage to pointing and using the words we, us, and people more (see Figure 12). The difference between groups that are able and unable to express a common end is that the fulcrum of persuasion, originally centered on

\footnotetext{
${ }^{9} \mathrm{Cf}$. Fn. 3. Notice that there is no common end in Nowak's definition of cooperate. Since his concept of cooperation entails doing something for an individual instead of with an individual, it would be more accurate to say that a pro-operator is "someone who pays a cost, $c$, for another individual to receive a benefit, $b$ ".

${ }^{10}$ The percentages by session, respectively, are: $6.6 \%, 11.1 \%, 9.2 \%, 10.0 \%, 13.3 \%$, and $8.2 \%$.
} 
establishing the common end, shifts to establishing a common identity that presumes similar useful experiences with the end. In other words, the persuasive work that the language does is indirect when the common end cannot be directly expressed.

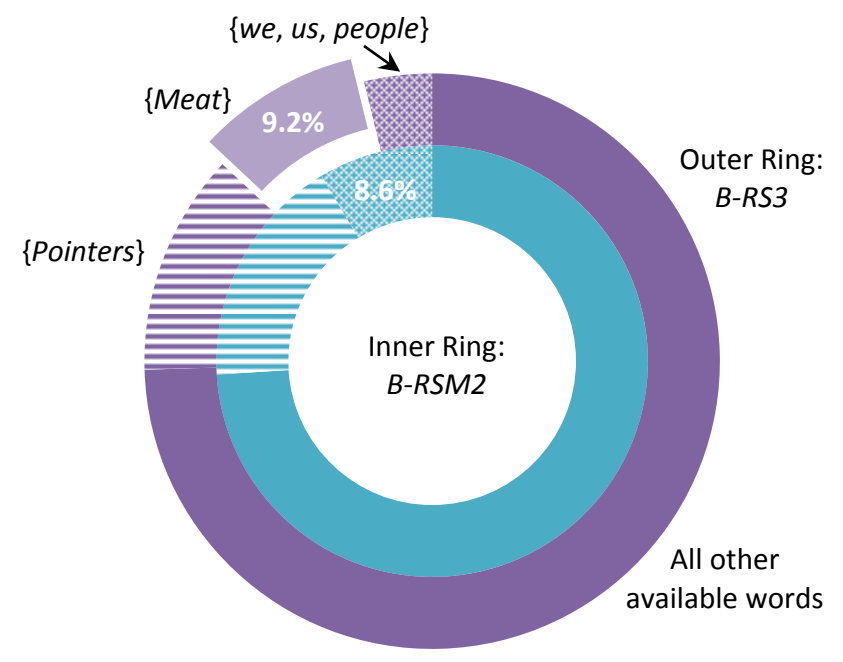

Figure 12. Distribution of Words Used in B-RS3 and B-RSM2

Expressing a common identity also makes cooperation possible, but that only happens in one group of four participants in the entire $B-R S M$ treatment. Using language to establish a common identity can indirectly function to maintain a band with a common end, but it is another workaround. The participants in the successful sessions of $B-R$ and $B-R S$ treatments refer to themselves as "meat people" 8 and 9 times, respectively. Why must language do this work of expressing an identity in $B-R$ and $B-R S$ ? Because the participants in these treatments, unlike those in $B$, cannot directly address the key problem that an established band faces, namely, "stay[ing] together." Again, the fulcrum of persuasion shifts, from continuing to work together to establishing a common identity that presumes common experiences with working together. ${ }^{11}$ Because Bickerton's recruitment problem persists in the face of competing interests and desires, participants in $B 2$ frequently and directly address problems with maintaining togetherness. The words stay and together are used 63 and 62 times, respectively, in B2. Combined, those two words account for a nontrivial $7.2 \%$ of the 1,716 words and symbols used in $B 2$.

The problem of social dilemmas is typically posed in terms of the challenge that a group faces in overcoming the immediate self-interest of its constituents. Self-interest of the individuals is the axiomatic point of departure and group cooperation the desirable but uncertain destination. Such is the consequence of modelling the problem as a mapping of individuals' actions into outcomes. Another consequence is that it purges from the problem two facts relevant for a group-maximizing solution: (1) Homo sapiens is the only species that regularly persuades non-kin to work together for a common end and (2) language is the uniquely human means for producing such agreement. If these observed facts serve as our point of departure, then the question isn't whether groups cooperate and by how much.

\footnotetext{
${ }^{11}$ Akerlof and Kranton (2000) discuss how the identity of social differences makes otherwise inexplicable outcomes possible.
} 
The question is, how do constituents persuade one another to cooperate? That groups of non-kin might fail, sometimes utterly so, at cooperation only makes it that much more compelling to understand why the minority of cases succeed. Without understanding the persuasive work that language does, we can never hope to explain or understand human cooperation, and, hence, our humanity.

\section{References}

Akerlof, George A. and Rachel E. Kranton. 2000. "Economics and Identity." Quarterly Journal of Economics, 115(3): 715-753.

Ashley, Gail M. 1999. "Geologists Probe Hominid Environments." Presidential Address to the Geological Society of America. Available here: http://www.geosociety.org/gsatoday/archive/10/2/pdf/i1052-5173-10-2-24.pdf. Last accessed August 3, 2015.

Bickerton, Derek. 2009. Adam's Tongue: How Humans Made Language, How Language Made Humans. New York: Hill and Wang.

Bickerton, Derek. 2014. More than Nature Needs: Language, Mind, and Evolution. Cambridge, MA: Harvard University Press.

Bickerton, Derek, and Eörs Szathmáry. 2011. "Confrontational Scavenging as a Possible Source for Language and Cooperation." BMC Evolutionary Biology 11(1): 261.

Bowie, Jill. 2008. "Proto-discourse and the Emergence of Compositionality," Interaction Studies 9:18-33.

Domínguez-Rodrigo, Manuel, and Travis Rayne Pickering. 2003. "Early Hominid Hunting and Scavenging: A Zooarcheological Review." Evolutionary Anthropology: Issues, News, and Reviews 12(6): 275282.

Domínguez-Rodrigo, Manuel, H.T. Bunn, A.Z.P. Mabulla, E. Baquedano, D. Uribelarrea, A. PérezGonzález, A. Gidna, J. Yravedra, F. Diez-Martin, C.P. Egeland, R. Barba, M.C. Arriaza, E. Organista, and M. Ansón. 2014. "On Meat Eating and Human Evolution: A Taphonomic Analysis of BK4b (Upper Bed II, Olduvai Gorge, Tanzania), and its Bearing on Hominin Megafaunal Consumption." Quaternary International 322: 129-152.

Ledyard, John. 1995. "Public Goods: A Survey of Experimental Research." In The Handbook of Experimental Economics. J. Kagel and A. Roth (Eds.). Princeton, NJ: Princeton University Press.

Nowak, Martin A. 2006. "Five Rules for the Evolution of Cooperation." Science 314(5805): 1560-1563.

Odling-Smee, F. John, Kevin N. Laland, and Marcus W. Feldman. 2003. Niche Construction: The Neglected Process in Evolution. Princeton, NJ: Princeton University Press.

Peltzman, Sam. 2015. "Future Directions for Research in the Coasean Tradition." Remarks available here: https://www.youtube.com/watch?v=dYJjX1tTCLg. Last accessed May 27, 2015.

Peltzman, Sam. 2000. “Prices Rise Faster than They Fall," Journal of Political Economy 108(3): 466-502. 
Vesterlund, Lise. Forthcoming. "Voluntary Giving to Public Goods." In The Handbook of Experimental Economics, Vol 2. John H. Kagel and Alvin E. Roth (Eds.). Princeton, NJ: Princeton University Press.

\section{Appendix. Experiment Instructions for the Bounded Treatment}

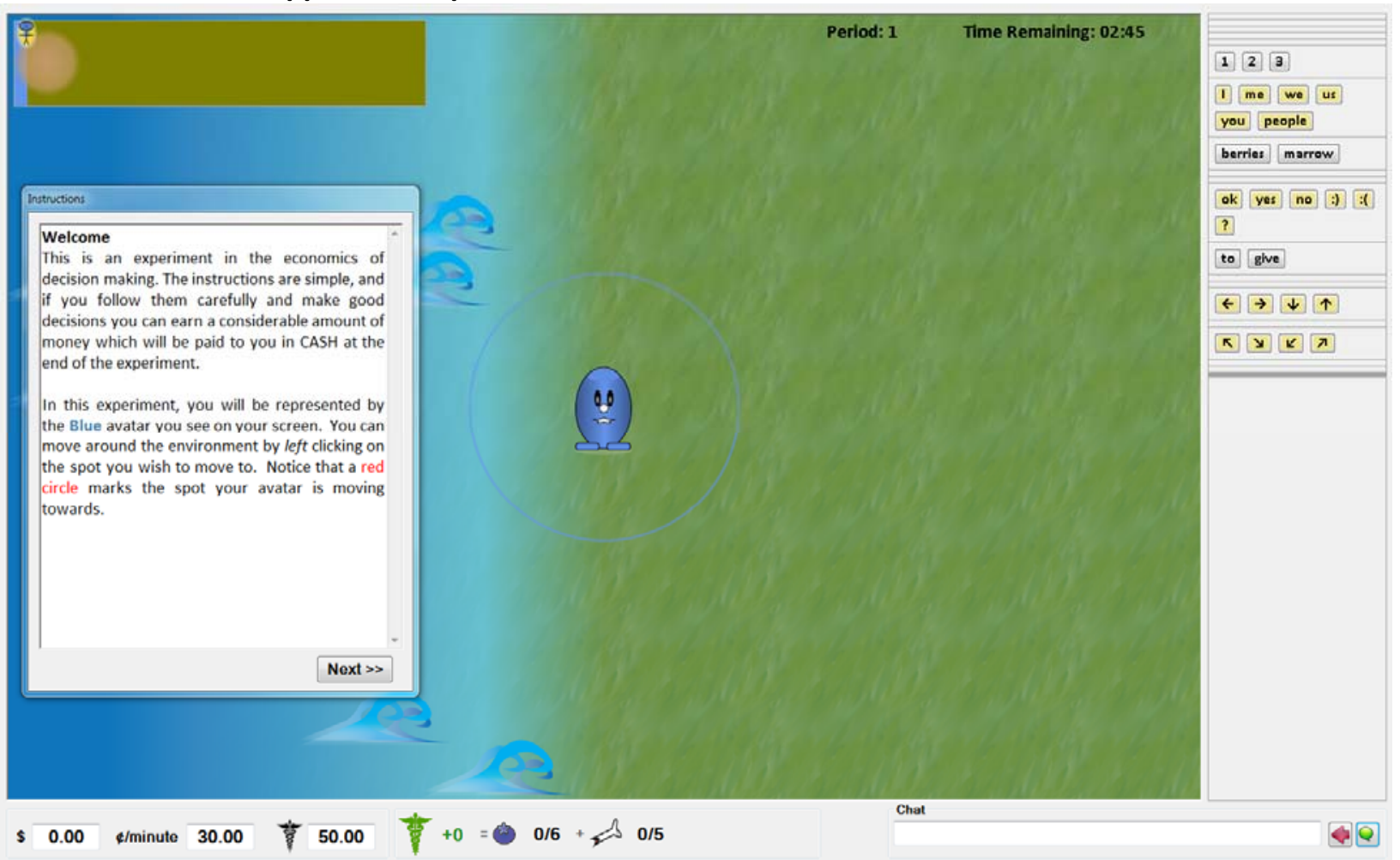



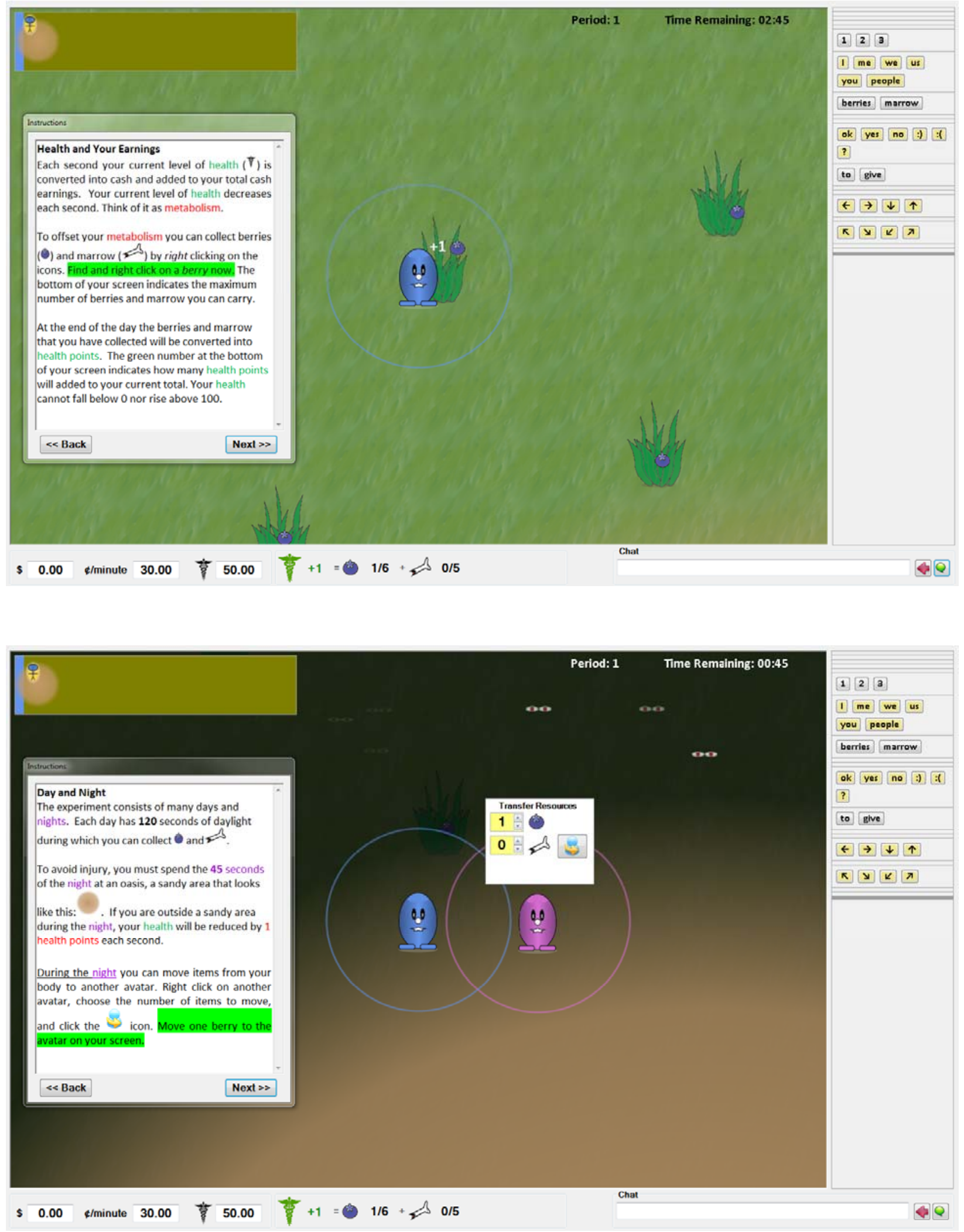

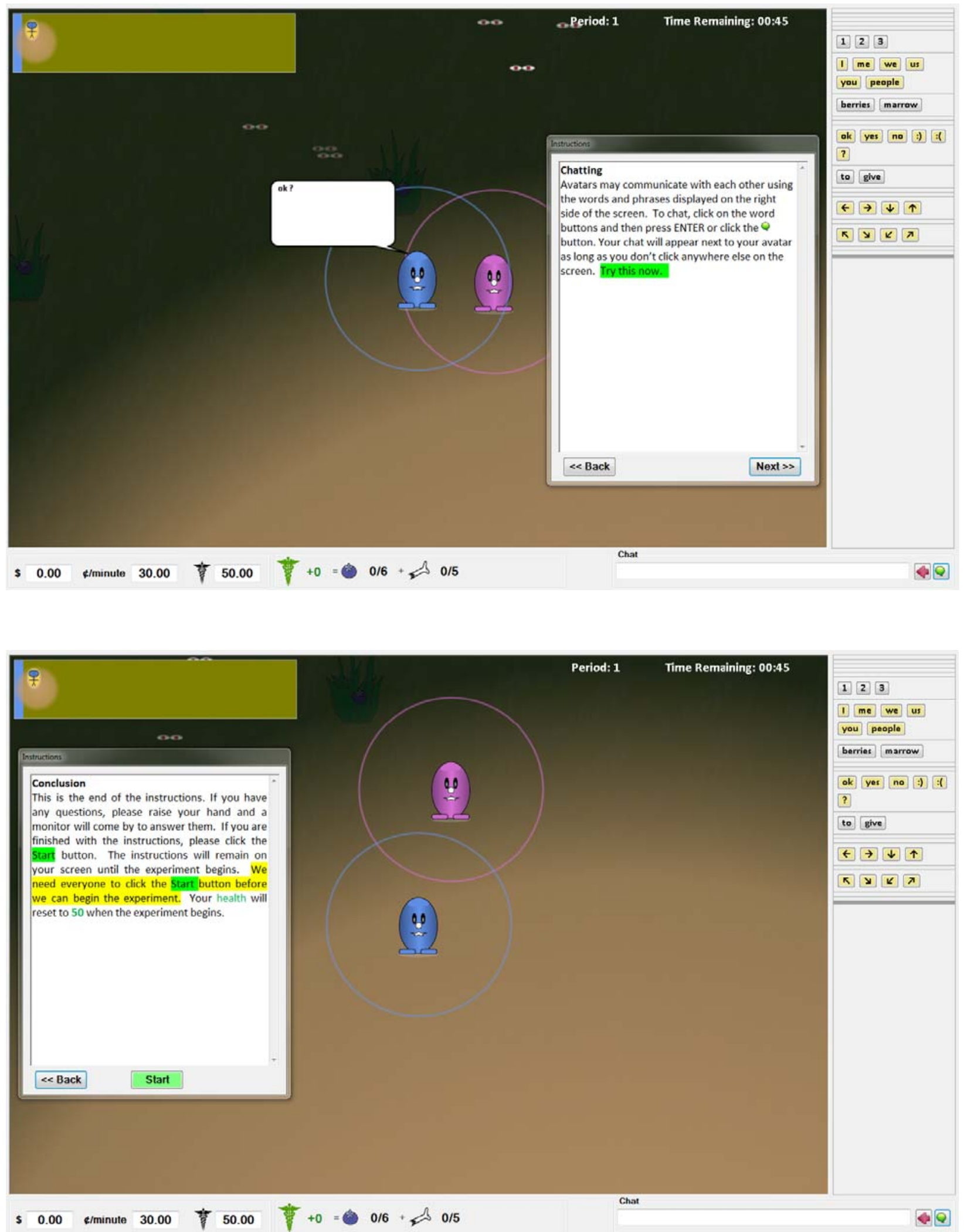